\title{
Forty Years after Laboratory Life $e^{*}$
}

\author{
Joyce C. Havstad ${ }^{\dagger}$
}

There is an ongoing and robust tradition of science and technology studies (STS) scholars conducting ethnographic laboratory studies. These laboratory studies-like all ethnographies - are each conducted at a particular time, are situated in a particular place, and are about a particular (scientific) culture. Presumably, this contextual specificity means that such ethnographies have limited applicability beyond the narrow slice of time, place, and culture that they each subject to examination. But we (STS scholars) do not always or even often treat them that way. It is beyond common for us to speak about what one or another laboratory study reveals about the laboratory, or "science" much more broadly. Given the contextual specificity of our ethnographic laboratory studies, what justifies this presumed generalizability? Initially, this manuscript surveys typical responses to this question, but then it pursues an unusual one: the potential replicability of ethnographic results. This potential is hereby explored, via an ethnographic replication attempt-one designed and conducted in order to test the generalizability of a particular laboratory study, that of Latour and Woolgar's classic Laboratory Life (1979). The results of the ethnographic replication attempt are reported, and a remarkable degree of replicability is established.

\section{Keywords}

ethnography $\bullet$ generalizability $\bullet$ Laboratory Life $\bullet$ laboratory studies $\bullet$ replicability $\bullet$ science and technology studies

\section{The Motivating Question}

Ethnographic laboratory studies are an important part of the ongoing science and technology studies (STS) tradition. But to what extent can the results of a particular laboratory study be generalized to other contexts? In other words, do STS ethnographies have any so-called “external validity" (Campbell and Stanley 1966; Calder, Phillips, and Tybout 1982), or perhaps

*In 1988, Ian Hacking wrote: "Soon it will be time to write 'Ten Years after Laboratory Life" (Hacking 1988, 277). Apologies for the decades-long delay.

${ }^{\dagger}$ Department of Philosophy, Oakland University, 146 Library Drive, Rochester, MI 48309, USA, jhavstad@oakland.edu (10 https://orcid.org/0000-0003-1923-7860

Received 9 August 2018; Revised 8 February 2019; Accepted 24 May 2019

doi:10.3998/ptpbio.16039257.0012.003 
“transferability" (Guba 1981; Lincoln and Guba 1982, 1985)? If so, what determines the range and scope of the generalizations they support?

One might be tempted to simply dismiss this question outright, as wrong-headed. 1 This is because laboratory studies in STS tend to wear their contextual specificity on their sleeve, so to speak, and presumably this contextual specificity nips (or ought to) the question of wider applicability in the bud. The argument goes something like this: STS ethnographies are conducted at a particular time, in a particular place, and of a particular scientific culture - and they do not, in general, hide this fact. When ethnographic results are reported, such reports invariably include a forthright statement of when and where and how the study was conducted. Usually this happens somewhere in the initial framing of the study:

The focus of our study is the routine work carried out in one particular laboratory. The majority of the material which informs our discussion was gathered from in situ monitoring of scientists' activity in one setting. (Latour and Woolgar [1979] 1986, 27)

The choice of the laboratory used in the present study was dictated by the opportunity to be accepted as an intruder (no matter how talkative or ignorant); and the choice of a group to trouble with my constant presence was determined by the willingness of one scientist in particular to serve as my informant throughout the period of observation. The observations were conducted from October 1976 through October 1977 at a government-financed research centre in Berkeley, California. (Knorr Cetina 1981, 24)

The volume is a descriptive study of social activities in a neurosciences laboratory which focuses on how electron-microscope phenomena were made sensually available and objectively accountable. It is based on fieldwork I conducted in the laboratory during 1975 and 1976. (Lynch 1985, xiii)

As these quotes demonstrate, the authors of such studies are well aware of the contextual specificity of their ethnographic methodology. Therefore (the proposed dismissal goes), such studies are neither designed nor intended to have wider applicability; to even ask about the extent of the generalization they might support is to fail to appreciate their contextual nature.

But this way of dismissing the initial query is specious. This is because-despite routine and open declarations of the specific contexts in which such ethnographies are conducted-their results are frequently interpreted by both authors and commentators as having far broader scope. The authorially-intended interpretive breadth of even early ethnographic results is evident in the reporting of such results:

Our contention is that many aspects of science described by sociologists depend on the routinely occurring minutiae of scientific activity. Historic events, breakthroughs and competition are examples of phenomena which occur over and above a continual stream of ongoing scientific activities. (Latour and Woolgar [1979] 1986, 27)

In the chapters which follow, I shall attempt to establish the symbolic, contextually contingent and constructive character of the scientific manufacture of knowledge I have introduced here. (Knorr Cetina 1981, 16)

\footnotetext{
${ }^{1}$ As several anonymous reviewers have.
} 
Besides debunking an image of "The Scientist" that admittedly served the purpose of scientific autonomy and proved invaluable as an educational prod and a defense against the assaults of creationists, among others, lab studies have raised to a new level the discussion of such traditional topics as rationality, consensus formation, discovery, and scientific controversy. Sociologists can now treat these topics as matters to be observed and described in the present, and not as the exclusive property of historians and philosophers of science. (Lynch 1985, xiv)

These studies are contextually specific, certainly; but their results are nonetheless both perceived and presented as generalizable. Here is a more recent example of an author acknowledging both these points at the very same moment-simultaneously disclosing the somewhat narrow context of their study, while also identifying the broader concept they hope to illuminate with said study:

The laboratory that is the focus of this book began at Cornell University in 1934, or in 1946, or in 1976, or even at some other time or pace, for that is part of the question: Just what is the laboratory? (Doing 2009, 3-4; italics original)

The motivating question of this paper is: How do we, as STS scholars, manage to get our hands on both of these things at once? Or, to deploy the usual jargon: How does the deeply grounded, particularly observed, thickly described, contextually specific nature of an STS ethnography translate into a broadly relevant, generally applicable, thinly conceptual, wide characterization of scientific practice? Put more simply: What makes a laboratory study representative - and of what?

\section{Possible Responses}

This is not a new question. Here is an early, entertaining response to it:

Throughout the rest of the book, I shall talk about "science" and "technology" without any further qualification in the spirit of grounded theorizing which proves so seductive to close observational studies. The well-disposed reader may want to remember that these observations have been conducted with a handful of scientists in one problem area at one research laboratory (the ill-disposed readers will recall this on their own). (Knorr Cetina 1981, 26)

Whether we need this reminder (as a well-disposed reader) or not (as an ill-disposed one), this is a response which acknowledges the issue at hand without actually resolving it. So, now that we have been reminded of the existing tension, in this domain, between specificity (of STS ethnography) and generality (of resulting "science" and "technology" talk), what should we do about it? Note that this tension is not an external one-being imposed upon STS practice from without; rather, it is an internal one-arising from two opposing elements within STS practice. In response to this tension, we could:

1. Keep eating our (specific) cake and (generally) having it too.

2. Deny the contextual nature of ethnography, in order to support our generalist conclusions based on said ethnography.

3. Embrace the contextual nature of ethnography and go radically local, abandoning even the pretense of drawing generalist conclusions based on it. 
4. Attempt to explain how situated ethnographic studies might produce widely generalizable results.

To accept option 1 without first exhausting the other potential responses is to be intellectually negligent. ${ }^{2}$ It is not easy to see how option 2 could even be attempted, given how markedly constrained ethnographic methods are by specifics such as what a limited number of observers can individually watch, which participants are available to be interviewed, how many sites can be visited, etc. 3 Option 3 has been pursued (e.g., Woolgar 1982; Latour 1988) and comes at a very high general price (see Guala 2003), along with significant domain-specific costs-such as needing to entirely change how we talk about what STS ethnographies can and do show about scientific practice. ${ }^{-1}$ If we (STS scholars) can get away with it, then securing option 4 offers the most promise-in terms of preserving intellectual integrity, maintaining traditional ethnographic practices, and supporting the usual presumptions of generalizability. It is therefore unsurprising that this fourth style of response-attempting to explain how situated ethnographic studies might produce widely generalizable results-is the dominant one. It runs both explicitly and implicitly throughout much of the STS literature.

But the supposed means by which specifically-situated and highly contextual ethnographies purportedly inform us about science in general are subtle, tenuous, vague, and various. For instance: one might appeal to the role of "grounded theorizing" in the conducting of ethnographic laboratory studies, as Knorr Cetina does in the above quote $(1981,26)$. But grounded theorizing (Glaser and Strauss 1967; Clarke 2005) is a method by which theory is developed from data (rather than the supposedly traditional method, according to which theory is first developed and then relevant data which bears on the theory is sought). Even grounded theorizing is based on contextually-gathered data (whether quantitative or qualitative), and theories that are "grounded" by such data are first and foremost accounts of how to explain that particular data. To presume that relevantly similar data would be produced in other contexts, and that the same "grounded" theory would thereby apply, is to assume rather than establish generalizability.

Alternatively - when going in search of a warrant for generalizing from the results of a particular ethnographic laboratory study to "science" much more broadly speaking-one might appeal to any or all of a trio of related distinctions. For one, it is possible that the distinction between idiographic and nomothetic knowledge (à la Windelband [1894] 1980) could help. 6 For another, maybe ethnographic practices contain not just elements of individuating method, but also those of generalizing method (à la Rickert [1899] 1962). Finally, there is the distinction between thin and thick description (à la Ryle 1968a, 1968b). It is possible that such distinctions apply to our problem - that some bits of ethnographic knowledge are nomothetic knowledge (knowledge of law); that some elements of ethnographic method are generalizing method (method that selects for shared features); that some aspects of thick ethnographic description support "broad assertions" (Geertz 1973, 28)—but possibility does not establish actuality. Even if, for instance, the nomothetic nature of ethnographic knowledge were actually established (which would be a real surprise), then some warrant for generalization would indeed be established-but questions

\footnotetext{
${ }^{2}$ As Hammersley (1989) put it: "These questions are not novel, but I find them increasingly troublesome. Even more troubling is what seems to me to be complacency on the part of qualitative researchers towards these questions" (4).

${ }^{3}$ Nonetheless, I welcome attempts to pursue option 2.

${ }^{4}$ The fact that it comes at a high price does not necessarily take the option off the table.

${ }^{5}$ In terms of implicit stances found in the literature: it is either faith that option 4 will come through, or acceptance of option 1 which dominates here. I choose to interpret neglect of this tension as holding out for option 4 rather than endorsement of option 1.

${ }^{6}$ As a reviewer has suggested.
} 
about the range of generalization would remain. Nomothetic knowledge is constraining where it applies. But where does it apply? Similarly, generalizing method does identify shared features among a set of phenomena or objects of study. But what outside the studied set shares those features? About broad assertions based on thick anthropological description, Geertz himself writes that "Only short flights of ratiocination tend to be effective in anthropology; longer ones tend to drift off into logical dreams, academic bemusements with formal symmetry" $(1973,24)$. Precisely how far from the original point of departure can one fly on these "short flights," and in what direction? Appeal to any of these three distinctions can establish the possibility of warranted generalizability for ethnographic results; but such candidate appeals do not themselves establish warranted generalizability in fact and extent. ${ }^{8}$

Perhaps the most subtle and yet widespread appeal to be made is to reflexivity, as the means by which contextually-specific ethnography might warrant its generalizability, and establish its range. Here is an early statement of what is meant by "reflexivity" in ethnographic laboratory study:

Our particular use of an anthropological perspective on science also entails a degree of reflexivity not normally evident in many studies of science. By reflexivity we mean to refer to the realization that observers of scientific activity are engaged in methods which are essentially similar to those of the practitioners which they study. (Latour and Woolgar [1979] 1986, 30)

Here the authors of Laboratory Life claim to be using methods to study science which are "essentially similar" to those of the scientists which they are studying. Scientific method supposedly produces scientific results, and scientific results are supposed to be generalizable, so perhaps the "essentially similar" methods of the social scientist correspondingly produce "essentially similar" results-with attendant generalizability.

Since it was first published in 1979, Laboratory Life has been cited more than sixteen thousand times. ${ }^{8}$ Its claim to reflexivity has been variously foreshadowed, embraced, echoed, critiqued, expanded upon, satirized, reapplied, rejected, dissected, and directed (Garfinkel 1967; Bloor 1976; Barnes 1981; Woolgar 1981a, 1981b; Mulkay 1984; Doran 1989; Pinch 1993; Lynch 2000; Finlay 2002). Yet laboratory studies are still undertaken and understood by STS scholars as fundamentally reflexive exercises:

Just as natural scientists act on and with scripts, materials, methods, and machines, so does the ethnographic researcher act on and with her assembled research subjects, inscription devices and traces, also in the laboratory. (Garforth 2012, 267)

So, interrogation of the concept of reflexivity has not led to its abandonment in STS practice. The relevant question for this paper is: does the presence of a reflexive attitude, amongst STS scholars who conduct ethnographic studies of the laboratory, warrant the generalizability of their ethnographic results?

Not by itself, it does not. To say that the methods of the ethnographer in the laboratory are "essentially similar" to those of the practitioners being studied is to imply that the two methodological sets are related to one another, but not precisely the same. And even if this claim of

\footnotetext{
${ }^{7}$ Consider even a bit of nomothetic knowledge as well-established as the Ideal Gas Law (Clapeyron 1834). Certainly, this is a law that constrains the behavior of ideal gases. But which substances are those? Among the many gases that we encounter, which are similar enough to the "ideal," such that the Ideal Gas Law at least somewhat constrains and predicts their behavior? This is a question about range of application.

${ }^{8}$ Once again, I welcome attempts to secure option 4 via evolution and development of these concepts.

${ }^{9}$ According to Google Scholar on July 4, 2019 at 8:45pm EDT, Laboratory Life has been cited 16,572 times.
} 
"essential similarity" were interpreted to mean something like "similar to those of science in all essential respects," this would still not be enough to establish warranted generalizability of ethnographic results. This is because warranted generalizability, even of scientific results, relies on external validity (in quantitative terms) or transferability (in qualitative ones). 10 Establishing (rather than assuming) applicability requires demonstrating that results are replicable in other contexts than the precise ones in which they were originally produced.11 Finally, identifying which other contexts support replicability establishes range.

In sum, there is no current, compelling, and established justification for the oft-presumed generalizability of ethnographic laboratory study results in STS scholarship. Nor has there been any clear establishment of the supposed range of such generalizations. But this survey of potential, theoretical warrants for generalizability has suggested a possible, empirical route for securing option 4.12 The best test of applicability is replication-usually in circumstances that are relevantly similar to but still somewhat distinct from those of the original study. Replicating the original study too closely fails to establish much in the way of range; moving too far from the conditions of the original study destroys any reasonable expectation of replication. The trick is to position the replication just right: close enough to sustain some hope of replication, but far enough away to extend the original study's range of warranted application.

Almost seventy years ago, the sociologist Raymond W. Mack sounded a call for replication research in sociology (Mack 1951).13 This paper documents an ethnographic replication attempt: a laboratory study conducted under conditions relevantly similar to but still somewhat distinct from a previous STS ethnography. The aim of the replication study was to test the presumed generalizability of the original, ethnographic results- to see whether there is any rea-

\footnotetext{
${ }^{10}$ Though see relatively recent discussion of what might constitute alternative strategies for "resituating 'local' knowledge" (Morgan 2014, p. 1013). This discussion of how to translate case-study material from one context to another is quite metaphorical: the proposed strategies are that of building "bridges and stepping stones," "ladders," and "constructed or exemplar representatives." Surrounding discussion is not entirely clear about if or how either generalizability or representativeness is warranted by such strategies (as opposed to such strategies relying or trading on generalizability or representativeness instead).

${ }^{11}$ In case anyone is under the impression that replicability applies only to the quantitative standard of external validity, but not to the qualitative standard of transferability, here are the creators of the alternative standard on what it takes to establish applicability in qualitative research: "To determine the extent to which transferability is probable, one needs to know a great deal about both the transferring and receiving contexts, to have what Geertz (1973) has dubbed 'thick description' about each. If the thick descriptions demonstrate an essential similarity between two contexts, then it is reasonable to suppose that tentative findings of Context $\mathrm{A}$ are also likely to hold in Context B (although, to be safe, an empirical test of that presumption should be made)" (Guba 1981, 81); "The best advice to give to anyone seeking to make a transfer is to accumulate empirical evidence about contextual similarity; the responsibility of the original investigator ends in providing sufficient descriptive data to make such similarity judgements possible. Even if the applier believes on the basis of the empirical evidence that sending and receiving contexts are sufficiently similar to allow one to entertain the possibility of transfer, he or she is nevertheless well advised to carry out a small verifying study to be certain" (Lincoln and Guba 1985, 298; italics original).

${ }^{12}$ This was the option of attempting to explain how ethnographic laboratory studies might produce widely generalizable results. It seemed worth pursuing because it alone offered the combined possibility of intellectual integrity, continued deployment of ethnographic methods, and warranted talk of generalization. Regardless, I will not mind if other STS scholars prefer to pursue either option 2 or 3 instead. Nor will I mind if they wish to pursue option 4 in a different way than I do here. The only option I decry is option 1.

${ }^{13}$ For an articulation and defense of the scientific criterion of replication, see Merton (1942), or Shapin and Schaffer (1985). This paper will largely ignore the so-called "reproducibility crisis" (Baker 2016), because that crisis itself presumes the ideal of replicability. Extensive critique and eventual abandonment of that standard for scientific studies could obviate the need for STS studies to themselves meet it ... however, we are not there yet. So far, the "crisis" is mainly an endorsement of fidelity to the standard of replication.
} 
sonable expectation of the laboratory study's replicability—and if so, to establish some warranted range for generalization. 14

\section{The Original Laboratory Study}

From October of 1975 to August of 1977, Bruno Latour conducted an ethnographic study of a neuroendocrinology laboratory at the Salk Institute for Biological Studies in La Jolla, California. In 1979, Latour and Steve Woolgar published their results. 15 The replication study reported here is based on a new set of ethnographic data obtained at the same institution (the Salk), in a related but distinct kind of laboratory (both endocrine-focused, but one more neurological and the other more genetic), and at a very different time (more than three decades later). 16 This replication study is not, nor was it intended to be, a revisit (à la Burawoy 2003). 17 Latour

\footnotetext{
${ }^{14}$ See Ayar, Bauchspies, and Yalvac (2015) for an interesting, alternative type of attempt-one that (reflexively) uses the scientific tool of meta-analysis to evaluate the generality of various ethnographic results, such as material culture and discursive activity.

${ }^{15}$ The full title of the first edition of the book was Laboratory Life: The Social Construction of Scientific Facts (Latour and Woolgar 1979). A revised edition was published in 1986, now titled Laboratory Life: The Construction of Scientific Facts (Latour and Woolgar [1979] 1986).

${ }^{16}$ This study was approved by the Institutional Review Board of the University of California, San Diego (Project \#091269SX). The ethnography was conducted during a period spanning just over two years. The ethnographer was trained and supervised in the conducting of the ethnography by experienced STS scholars and as part of a larger, retrospective oral history project dedicated to the anniversary of a related institution. IRB approval for the larger project was granted on September 2, 2009. IRB approval for the conducting and recording of formal, structured interviews with human research subjects was granted from February 3, 2010 through February 3, 2011. IRB-approved consent forms were obtained. Throughout the duration of the study, twenty-one interviews were conducted with members of the laboratory under study — six with the PI of the laboratory and fifteen with others. Most interviews were at least an hour in length and some ran for several hours. Each formal interview was structured by use of a seven-page questionnaire split into thirteen sections:
}

Background

Recruitment

Early Years

Changes

Laboratory System

$\mathrm{Lab}$

Key Individuals

Collaboration

Education

Evaluation of Career and Time

Closing Interview

Questions for Women and Minorities

Questions about Funding

Each of the thirteen sections contained somewhere between three and twenty-two candidate queries. Throughout the ethnographic study period, observation was conducted on a near-weekly basis within the laboratory. All recordings and field notes from the period of study have been preserved.

${ }^{17} \mathrm{~A}$ reviewer has asked why this replication study was not conducted in the same laboratory as the original. The answer is because I thought that would be attempting to replicate the original study under conditions too far from the initial ones. Latour did his ethnographic work in Roger Guillemin's laboratory at a very specific time in the trajectory of that lab-he finished his observations just two months before Guillemin won his Nobel Prize, in October of 1977. A lab headed by a research heavyweight chasing the biggest prize in science is qualitatively different than one headed by a proven Nobel Prize winner; just as a lab with a green PI and no graduate students or postdocs is very different from a lab headed by a PI with a great deal of prestige and experience but on the verge of retirement. Comparing the "same" lab but at qualitatively distinct moments in its trajectory is not necessarily replication. I chose to conduct my ethnographic replication also at the Salk, and in a laboratory that was close to being at the same point in its trajectory as Guillemin's had been when Latour did his. This establishes enough 
and Woolgar claim to have conducted their ethnography and analyzed the resulting observations without taking the validity of the scientific facts under construction for granted-adopting what has been called "the technique of 'anthropological strangeness'" (Tibbetts and Johnson 1985, 745) — and this replication study has adopted their methods.

In the decades since Latour and Woolgar conducted their fieldwork and analyzed their ethnographic data, many science studies scholars have followed in their footsteps, as well as gone beyond the authors' foundational work. Many STS scholars have conducted their own laboratory studies (including but not limited to Knorr Cetina 1981; Lynch 1985; Traweek 1988; Fujimura 1996; Bowker and Star 1999; Doing 2009). Still others have developed the tools of ethnographic methodology (e.g., Conefrey 1997; Gooday 2008; Garforth 2012; Stephens and Lewis 2017). Latour and Woolgar's analysis of the ethnographic data offered in Laboratory Life has also inspired extensive evaluation. Some of the key concepts offered in Laboratory Life-such as the daily activity of science, origin stories, statement types, and cycles of credithave been generally well-received, broadly endorsed, and gradually taken up by science studies scholars (see Knorr Cetina 1981; Shrum 1984; Haraway 1987; Oldroyd 1987; Lynch 2000; Horn 2001; Law 2008; Livnat 2009; Ihde 2015). Other concepts-like literary inscription, fact construction and microprocessing, and the creation of order out of disorder-have been much more controversial, inspired fierce debate, and led to ongoing dispute (e.g., Tilley 1981; Grenier 1983; Golinski 1990; Weinert 1992; Sismondo 1993; Murphy 1994; Hacking 1999). Many STS scholars have responded in a piecemeal way to the concepts for understanding scientific practice offered by Latour and Woolgar in Laboratory Life-accepting some while rejecting others. Hacking (1988), for instance, accepts cycles of credit but rejects the supposedly "irrealist" entailments of fact construction.

This kind of interplay of reactions, between endorsement and dispute, should not be all that surprising-especially with an influential book like Laboratory Life. What is surprising is that the basis for and extent of generalization of these concepts has not itself been more thoroughly established-even for those most popular concepts that have been broadly accepted as coherent and consistent, and in a field that has long recognized the role of replication in science (e.g., Collins 1975, 1968; Shapin \& Schaffer 1985; Radder 1992). 18 The ethnographic study conducted by Latour and Woolgar is now about forty years old. Its data was collected at a particular time, in a particular place, and about a particular culture that has no doubt changed at least somewhat in the ensuing decades. Nonetheless, Latour and Woolgar's results have been scientized - they have been treated with presumed generalizability. In case there is any doubt about the contextually-situated results of Laboratory Life in particular being interpreted as broadly representative of scientific practice, here is a selection of quotes from first the authors, and then a host of commentators spanning several decades:

Our initial visit to the laboratory established the central importance of literary inscription for laboratory activity: the work of the laboratory can be understood in terms of the continual generation of a variety of documents, which are used to effect the transformation of statement types and so enhance or detract from their fact-like status. (Latour and Woolgar [1979] 1986, 151)

Thus Latour and Woolgar present science as conjecture, consideration of conjecture (treating it as a modality, asking about evidence and support for it) and then, if it

similarity for reasonable expectations of replicability, while introducing difference that can be used to establish range- since the research areas are not precisely the same, the personnel is entirely different, etc.

${ }^{18}$ The issue of basis for generalization of the results of Laboratory Life has not been entirely neglected, of course. Hacking, for instance, takes some initial steps down this road by asking just how "typical” Latour and Woolgar's case study really is (Hacking 1988, 290). 
survives this, its incorporation into the corpus of scientific knowledge. So far so good. (Tilley 1981, 122)

The claim is that all scientific knowledge is socially constructed and the result of the negotiations and interpretations of scientists. (Weinert 1992, 424)

The project is an attempt to understand the activities of the scientist as [s] he tries to 'create order out of chaos', from analogical thought-processes to negotiations within the laboratory, to the establishment of careers. (Sismondo 1993, 532)

Their ideas are based on a close observation of the work of scientists in an endocrinological laboratory, using a methodology adapted from anthropological research. Their description presents the scientific fact not as part of natural reality, but rather as the product of communication, interaction, and negotiations, and most especially, as the final result of a disciplinary consensus. (Livnat 2009, 378)

Purportedly, Laboratory Life is about the laboratory, science writ large, all scientific knowledge, activities of "the scientist," and the scientific fact, full stop. Its results are presumed generalizable - but what is the basis for this presumption? 19 Note that the issue of external validity (in quantitative terms) or transferability (in qualitative ones) is separate from that of internal validity (in quantitative terms) or credibility (in qualitative ones). The question of this paper is not: is Latour and Woolgar's interpretative conceptual framework plausible, given their

\footnotetext{
${ }^{19} \mathrm{~A}$ reviewer proposes that "general claims that follow from this work are logically valid because these contexts are parts/subset of other, bigger ones-i.e., $F$ happens in a science lab, allows for the inference that $F$ happens in science, if we understand a science 'lab' to be part of 'science'. So if $x$ is a subset of $X$, what we observe in $x$ we observe in $X$." Even granting that we understand science labs as parts of a larger science whole, this notion of general claims (such as the ones made above) logically following from particular ones is not correct. More generally stated existential claims logically follow, but nearby claims of actual generalization merely seem valid in virtue of ambiguity about what it means to be "in" something. To mistakenly endorse actual generalization in this kind of case is to commit the fallacy of composition.

To demonstrate: suppose that the relation between a science lab ' $x$ ' and science ' $X$ ' is indeed to be treated as a part/whole relation, and phenomenon ' $F$ ' is observed happening in $x$ (which is itself a part of the whole $X$ ). To infer from " $F$ happens in $x$ " to " $F$ happens in $X$ ” (because $x$ is a part of $X$ ) is logical only so long as we interpret " $F$ happens in $X$ " as an existential claim about there being some instance of $F$ which has happened somewhere in $X$. In making such an inference, we merely (re)describe the region in which $F$ has occurred in a more general way (as happening in $X$ rather than in $x$ ), but we do not thereby generalize the claim itself (we have still observed just one $F$ happening at one location, although we can describe that location more or less specifically).

Alternatively (since the reviewer offers both possibilities): suppose that the relation between a science lab ' $x$ ' and science ' $X$ ' is that of a subset/set relation instead, and phenomenon ' $F$ ' is observed happening in $x$ (which is itself a subset of the set $X$ ). It is logical to claim that "what we observe in $x$ we observe in $X$ " only so long as we interpret the inference from "we observe $F$ in $x$ " to "we observe $F$ in $X$ " as an existential one-a move from "there is some $F$ which has been observed in $x$ " to "there is some $F$ which has been observed in $X$." Again, we have now (re)described the region in which $F$ has been observed in a more general way; we have not actually inferred that anything more general is happening.

The crucial distinction at work here is best presented with the help of a concrete example. For instance: we observe a $\mathrm{g}$-force of 1 here on Earth, so we can appropriately say that "we observe a g-force of 1 on Earth." Since the Earth exists "in" space, however, we can also say that "we observe a $\mathrm{g}$-force of 1 in space." But this is misleading, and only works logically so long as our revised claim is understood as another existential claim ("there is some place in space where a g-force of 1 has been observed"), now put more generally than the original was. Understood as an actual generalization ("we observe a $g$-force of 1 on Earth, so we observe a g-force of 1 in space"), the revised claim is both invalid and false. In sum, to put something more generally is not the same as to generalize it.

I suspect the reviewer understands this difference, since they expand on their claim that "what we observe in $x$ we observe in $X$ " by saying that it "does not mean that this happens always, everywhere in science but that this happens somewhere, in science." This is indeed "a way in which these claims are 'valid' and correct to make," but to put them in such a way is to make these claims existential, not general.
} 
(ethnographic) data set? Rather, the question is: can a similar (ethnographic) data set be produced under relevantly similar conditions, and if so, does Latour and Woolgar's conceptual framework similarly fit that new data, as it did (or did not) fit the old? 20

\section{The Ethnographic Replication}

The rest of this paper will be dedicated to assessing the applicability of Laboratory Life, as revealed via an ethnographic replication attempt. Happily, the replicative attempt documented here shows a surprising degree of replicability for the original study - a result which should be reassuring for many STS scholars. ${ }^{21}$ This section presents a succession of detailed ethnographic observations (made by the author), documenting and comparing the new ethnographic data set with the original. The next section assesses how well Latour and Woolgar's proposed conceptual framework fits the new data, paying special attention to cases of differential fit (where the old data fits the framework well but the new data does not) and shared misfit (where neither the new nor the old data seems to fit the proposed framework especially well).

This ethnographic replication study is based on approximately two years of observation of and interviews with members of Principal Investigator X's gene expression lab at the Salk Institute (hereafter known as GEL-X).22 Gene expression is, like neuroendocrinology, a scientific field within molecular biology. And, like Roger Guillemin's lab where Latour observed, Principal Investigator X's lab is also a highly competitive and prestigious lab located at the Salk.

The Salk Institute for Biological Studies was founded by Jonas Salk, designed by Louis Kahn, funded by the March of Dimes, and built in La Jolla, California-with scientific research commencing in its first laboratory in 1963. The Salk has two main buildings perched on a cliff above Black's Beach and the Pacific Ocean. The buildings run parallel to each other east to west and are referred to as the North Building and the South Building. There is a stone courtyard

\footnotetext{
${ }^{20}$ As Lincoln and Guba (1985) put it: "How can one tell whether a working hypothesis developed in Context A might be applicable in Context B? We suggest that the answer to that question must be empirical: the degree of transferability is a direct function of the similarity between the two contexts, what we shall call 'fittingness'. Fittingness is defined as the degree of congruence between sending and receiving contexts" (124; italics original).

${ }^{21} \mathrm{I}$ am afraid nothing close to consensus about what constitutes a successful replication exists in the STS literature, and many contradictory accounts of 'replication' (and related terms) persist (e.g., Popper 1956[1934]; Hempel \& Oppenheim 1948; Lakatos 1970; Collins 1975, 1985; Franklin \& Howson 1984; Shapin \& Schaffer 1985; Mulkay \& Gilbert 1986; Radder 1992; Salmon 1998; Bogen 2001; Schickore 2011; Feest 2016; see Plesser 2018 for just one of many recent examples from science itself). Regardless, my sense is that a successful replication is one in which an original study's conclusion(s) can be justifiably redrawn, with at least a reasonably similar degree of fit, from a new set of data. So, if the original study produced its own data set, and conclusions were drawn based on that data set (some likely better supported than others), then a successful replication is one in which a reasonable expectation of deriving similar conclusions is fulfilled in a new context, based on a new data set, and for which the original conclusions fit the new data set approximately as well as the original conclusions fit the original data set (again, with some conclusions likely better supported than other, more speculative ones).

An account like this allows us to distinguish replicability from 'reproducibility', understood (as it often is) as the ability to redraw original conclusions from original data; and it allows us to distinguish replication proper from what some have called 'mere' replication (e.g., Gilbert \& Mulkay 1986). I also think that, on this sort of account, if the new data does not fit the original conclusions quite as well, or if the new data provides much better support than the original data did for the original conclusions (i.e., the new data supports the same original conclusions but with better fit), then in either case the new study has not precisely "replicated" the findings of the original. Perhaps in the former case we would say that replication has failed, whereas in the latter case we would say that the new study has gone beyond replication.

${ }^{22}$ At the time of Laboratory Life's original publication, Latour and Woolgar refrained from identifying the particular lab in which they conducted their ethnography, and all references to individuals in the lab were anonymized; that practice is replicated here. To pay homage, something of an attempt has also been made to present this new ethnographic data with at least an element of Latourian ethnographic flair.
} 

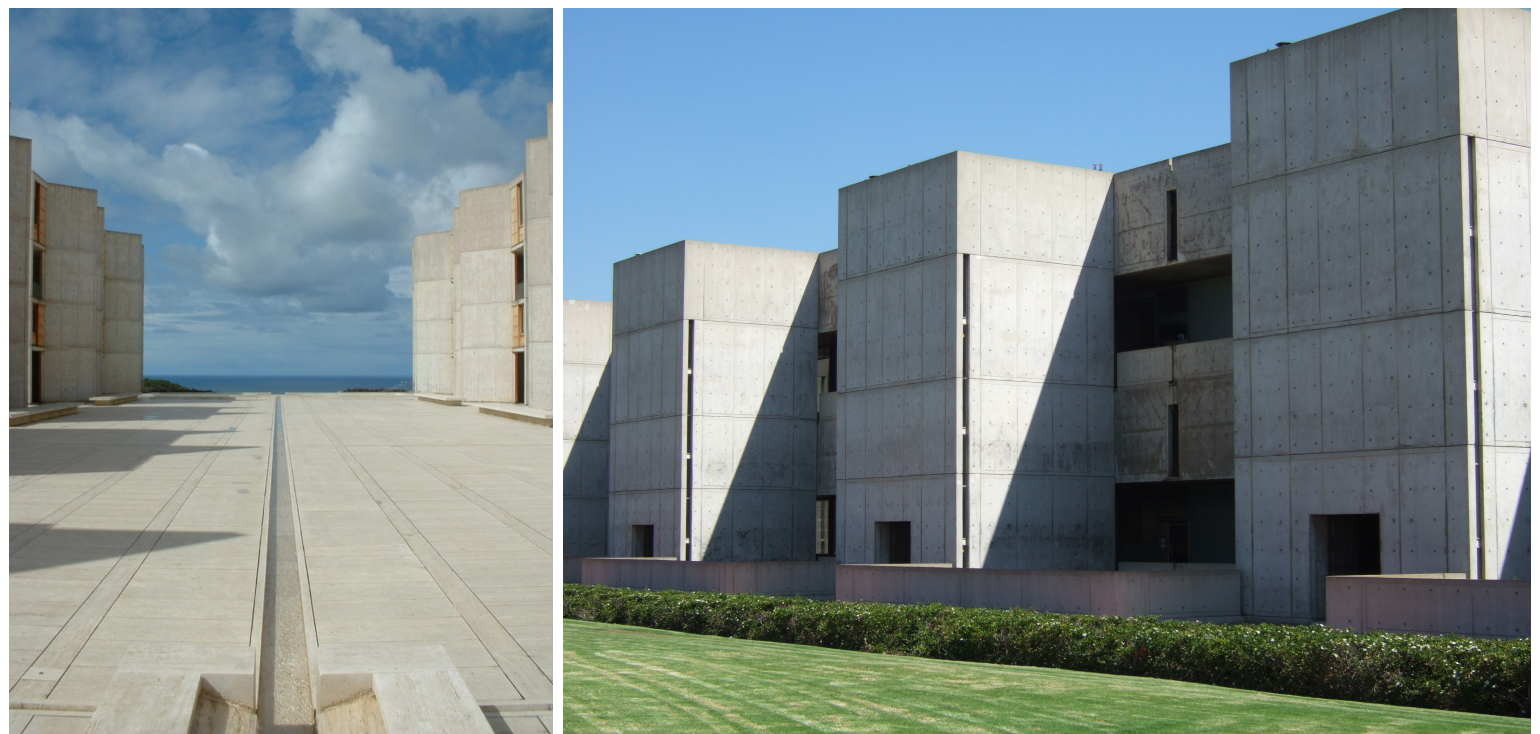

Figure 1: On the left, the Salk Courtyard, facing the Pacific Ocean; on the right, a view of the North Building from the lawn. Photos by author.

(made of travertine marble) between them. Standing at the east end looking west, there is a spectacular view of a green canyon, the water, and above this the sky, all framed by the tiered buildings of the Institute. East of the courtyard, behind the observer, is a newer building that houses the administration, conference halls, and some lab space. It is called the East Building. Figure 1 is pictures of the Salk campus.

Most of the Salk Institute's laboratories occupy the first, third, and fifth floors of the North and South Buildings. The second, fourth, and sixth floors are pipe space 23 - crammed with fridges, freezers, shakers, incubators, and tanks for cold storage. The third floor is actually the one that is level with the ground around the Institute. The second and first floors lie below the ground. At the first floor, underground, the two North and South buildings are connected by several tunnels. There are also courtyards outside the lower-level laboratories to let in light from above. Walking along the east tunnel there are cupboards, fridges, freezers, and kiosks labeled with names like Invitrogen, New England Biolabs, Ambion, and Fisher. ${ }^{24}$ Labs can send members down to a kiosk to enter a code and immediately retrieve required supplies. But the bulk of supplies are ordered via computer and delivered directly to the lab.

Principal Investigator X's gene expression lab (GEL-X) is on the fifth floor of the North Building. The "GEL" in GEL-X stands for Gene Expression Laboratory, and the letter which is here "X" would normally indicate the first letter of the last name of the lab's principal investigator (PI). There are four gene expression labs at the Salk (at time of writing), each doing work in the general field of gene expression but led by different principal investigators. All the GEL labs are located somewhat together on the fifth floor of the North Building.

There are wood-paneled offices for the PIs of the GEL labs located along the westernmost wall of the North Building, separated from the lab space by an outdoor hallway. Facing eastward and entering the main door to the laboratory, there is first a computer room and a kitchen, and then a large space filled with benches and equipment. Desks (with spots for up to 22 postdoctoral researchers and graduate students) stretch along the southern wall for the entire

\footnotetext{
${ }^{23}$ The space for ducts, conduits, machines, and the like which generally resides between those floors designated for personnel workspace in a building.

${ }^{24}$ Reps from these companies often appear in the laboratory, offering new kits or other equipment for laboratory members to try-as well as offering coupons, discounts, and other enticements to order.
} 
length of the laboratory. The lab benches (nine in total, fitting approximately four researchers each, one pair on each side of the bench) span the width of the lab space, perpendicular to the desks. The countertops are cluttered and the shelves crammed with vials, tubes, jars, and other supplies. The opposite wall, facing the desks, also holds packed shelves and chest freezers.

The wall is broken by gaps that lead into another lab space. These passageways are also crammed with more equipment and workstations for specific procedures. The first has polymerase chain reaction (PCR) machines on one side and the radioactive station on the other. Often the stations are so packed that there is no actual space open on the countertop. The next gap is a so-called "cold room": a walk-in refrigerator with cupboards for materials and shakers for more procedures. After this is the chemical weigh station. There are big containers of crystals and powders. There are mixers and a $\mathrm{pH}$ detector. Many of the solutions made in the lab are made here. Past this is the tissue culture room: a room with several sterile hoods (an overhead ventilation system for keeping things sterile while you work under them), some incubators and cold cases. After this there is another cold room, and then the back wall of the main lab space.

A row of centrifuges stretches to the left, and a wall of lab materials is on the right. There are carts with empty cages in front of the wall. These are brought up from what is colloquially called "the mouse house." This is where most of the animals in the Institute are kept, in large rooms full of cages, and supervised by members of the Animal Research and Development (ARD) department. Once brought up to the lab, animals cannot be returned for fear they will infect the rest of the population with germs from outside the mouse house. 25 When the cages are empty they are taken from the lab and placed in a giant rack on the bottom floor of the institute. Carcasses are also taken downstairs in plastic bags and left in freezers for disposal. Workers from ARD take the cages, clean and sterilize them in a giant underground autoclave, and then reuse them. The carcasses are destroyed.

Beyond the main lab space are more benches, part of a neighboring lab. Then there is another room with the robots for quantitative real-time polymerase chain reaction (Q-PCR), as well as a bench and a hood. Past this is another room with old equipment, supplies, and a few hoods for viral work. This is about where this lab's territory ends and another lab begins, although GEL-X has additional storage and work rooms scattered around the Institute. Altogether the main lab space of GEL-X occupies about one half of the fifth floor, in the southwest quadrant of the North Building.

In Laboratory Life, Latour and Woolgar included a detailed diagram of Guillemin's laboratory, which depicts the lab space as a sort of cellular entity with certain inputs and outputs (Figure 2). Latour and Woolgar note the various inputs as (proceeding counterclockwise from the top): mail, telephone, animals, chemicals, and energy. The sole output is articles. A diagram can also be provided for GEL-X, with inputs and outputs identified (Figure 3). Some of the inputs and outputs identified in Laboratory Life are preserved here, but some changes have also been made.

One change to the diagram is the fact that "people" and "money" have been added as inputs. Neither of these integral components were included in the original diagram, though Latour and Woolgar did acknowledge each in the text of Laboratory Life. For example, when discussing the diagram, the authors mention as another input "the technicians and doctors who comprised the

\footnotetext{
${ }^{25}$ Animals are often brought up to the lab alive so that their organs can be harvested under precise conditions that allow for various elements to be maximally preserved and for various tests to be run. Killing the animal and harvesting its organs often requires particular supplies (like dry ice and liquid nitrogen) which have to be constantly replenished during the work, and which are not kept where the animals are housed. Going in and out of the "mouse house" to fetch these supplies, not to mention conducting the harvesting operations themselves, would risk sterility in the housing space. So animals are usually brought up for killing.
} 


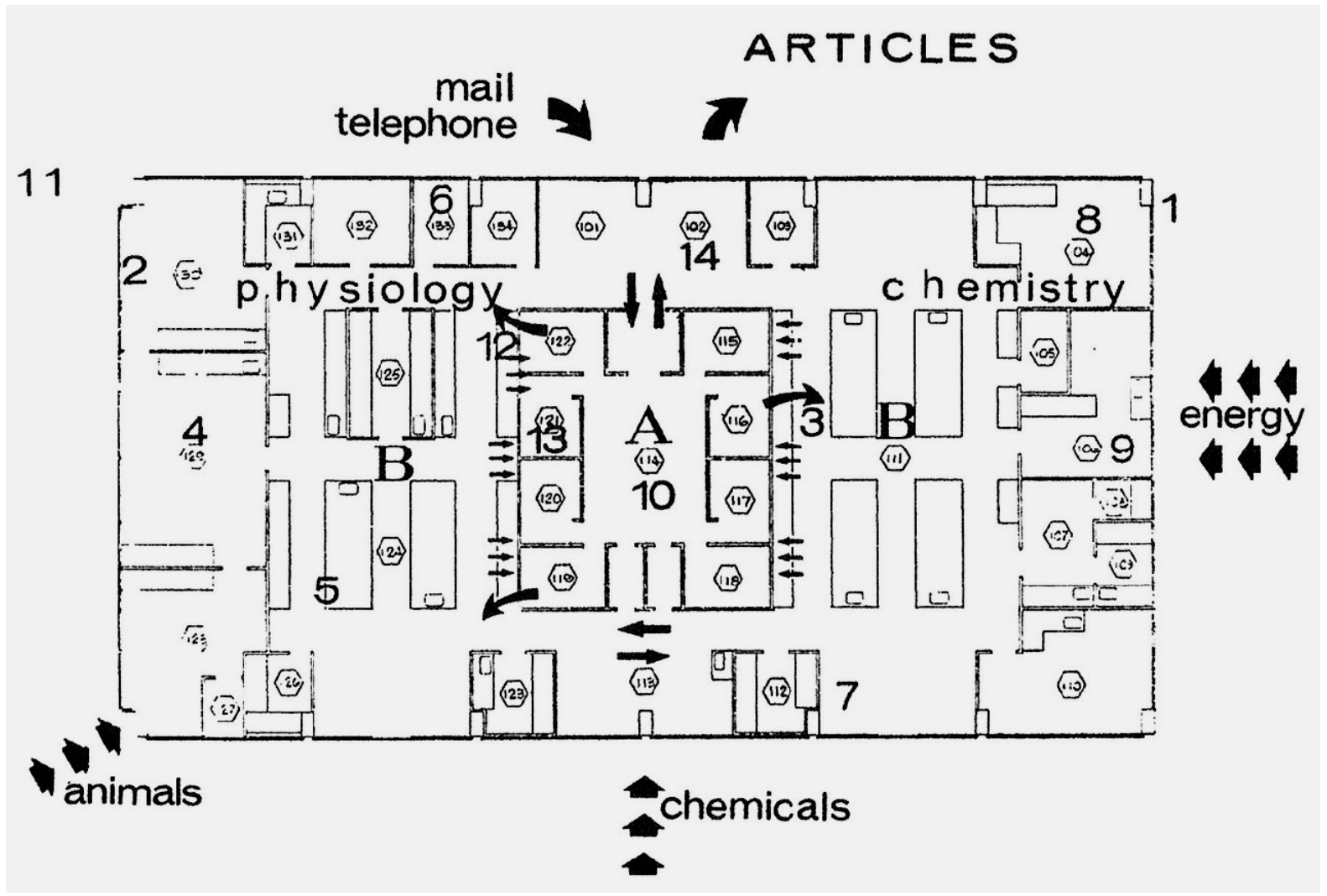

Figure 2: Diagram of the interior of Guillemin's laboratory (Latour and Woolgar [1979] 1986, 46). Reproduced with permission.

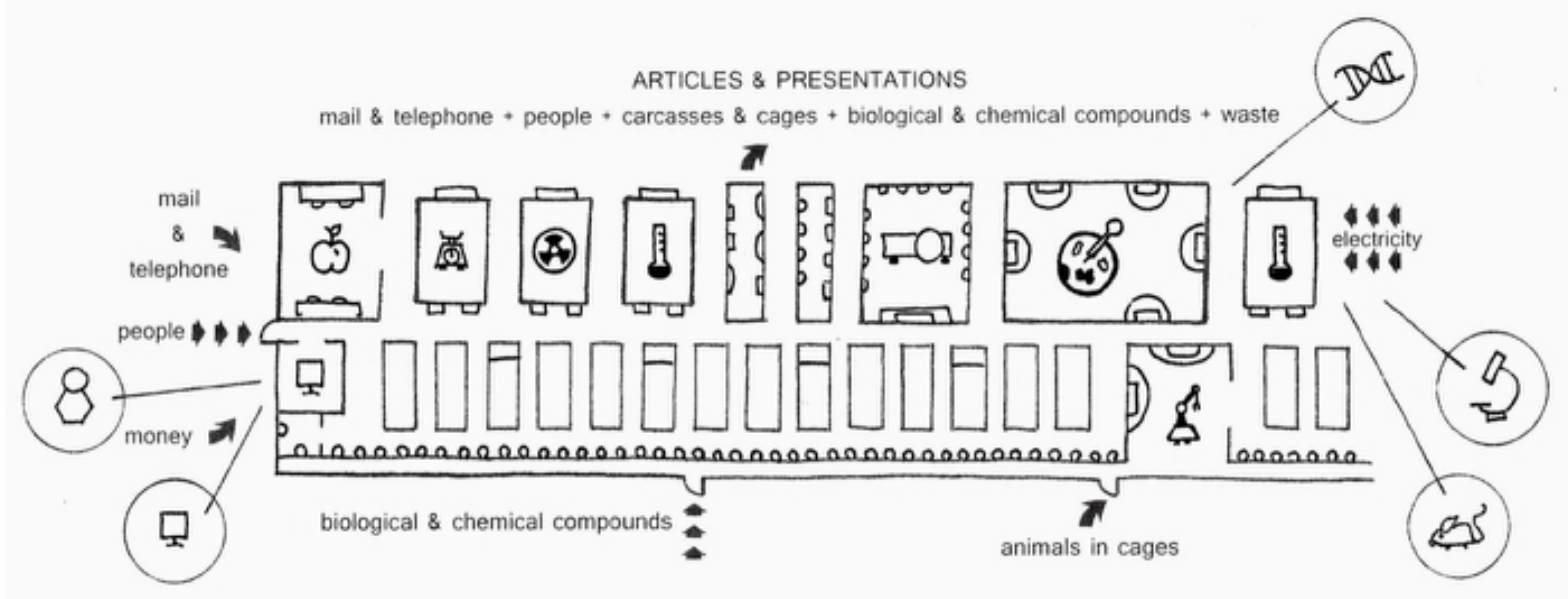

Figure 3: Diagram of the interior of the GEL-X laboratory. Satellite locations dedicated to (clockwise from top) sequencing, histology, animal care, computer processing, and offices for top personnel also depicted. Drawings by author. 
work force" (Latour and Woolgar [1979] 1986, 52). And in the observer's story (discussed in the next section), there is mention of funds: "cheques of taxpayers' money arrive periodically, courtesy of the NIH, to pay bills and salaries" (Latour and Woolgar [1979] 1986, 16). But neither are explicitly included in the diagram - perhaps the checks were considered part of the mail input; regardless, these omissions have been rectified in the newer diagram. And in keeping with the previous description of GEL-X, the input "animals" has been specified to "animals in cages," and the input "chemicals" has been expanded to "biological \& chemical compounds" because both kinds of compounds are critical inputs. Finally, the input "energy" has been replaced by "electricity," since other forms of (traditionally called) energy rarely enter the lab. For instance, food for either animals or persons is not allowed in the lab. Animals are brought up to the lab only to die-once removed from it, they cannot be returned to the mouse house. And people are technically not permitted to eat at their benches or desks-all food must remain in the kitchen. In total, the inputs include (again, proceeding counterclockwise): mail 26 \& telephone, people, money, animals in cages, biological \& chemical compounds, and electricity.

Perhaps the most obvious difference, however, is that the new diagram includes many more outputs than Latour and Woolgar's. This is simply because far more than just articles exit the modern laboratory. First, the statements which Latour and Woolgar identified as the primary focus of scientific practice are not only made in literary form, as articles; they are also made in spoken form, as conference presentations. Second, the only inputs which are not also outputs are money and electricity. Members of the lab send as well as receive (e)mail; they make as well as receive telephone calls. These people join the lab but they also leave it, often to form their own gene expression laboratory at another academic institution. Both the animals and the cages that enter the lab exit it as well, although the animals have inevitably switched from alive to dead. Chemical compounds and biological samples (most often plasmids) are shipped to other academic labs for further research. Finally, GEL-X produces quite a bit of waste, and this byproduct of the daily activity of science should not be overlooked (for a related discussion see Sterne 2007). Throughout the laboratory, there are many different kinds of waste, each with their own signage and methods of disposal: (normal) trash, food waste (from the kitchen), recyclables, biomedical waste (such as used petri dishes), sharps (like needles and broken glass), hazardous waste (such as syringes with viral solutions), and radioactive waste (like pipette tips used to extract an isotope). To summarize, as the figure shows, total outputs include: articles \& presentations, (e)mail \& telephone, people, carcasses \& cages, biological \& chemical compounds, and waste.

The diagram also serves to emphasize how big GEL-X really is. GEL-X takes up most of the fifth floor of the North Building, although there are still four other labs on the floor. Three of them run in sequence along the north side and the fourth fits into the leftover pocket at the east end. Technically, this isn't even the entirety of the laboratory: GEL-X is more distributed than is suggested by the floorplan alone. This is because the lab constitution also includes some satellite locations (as depicted in the figure above). There are several office areas in different locations throughout the building-including the office of the principal investigator. One set of office suites exists below and west of the actual lab space (on the fourth rather than fifth floor of the building). There are also satellite areas in which certain kinds of scientific activity crucial to the lab are performed. Some sequencing is now done in its own area at the Salk, and some animal procedures are performed where the animals are housed. This spatial fragmentation of the laboratory represents a significant variation in lab composition from the time of Laboratory Life.

${ }^{26}$ Let us stipulate that the category "mail," in this diagram at least, includes electronic mail, a.k.a. email. 


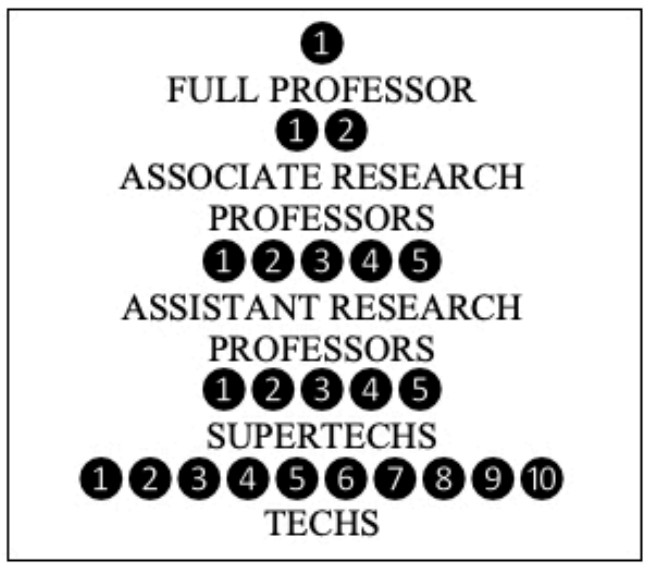

GUILLEMIN'S LAB
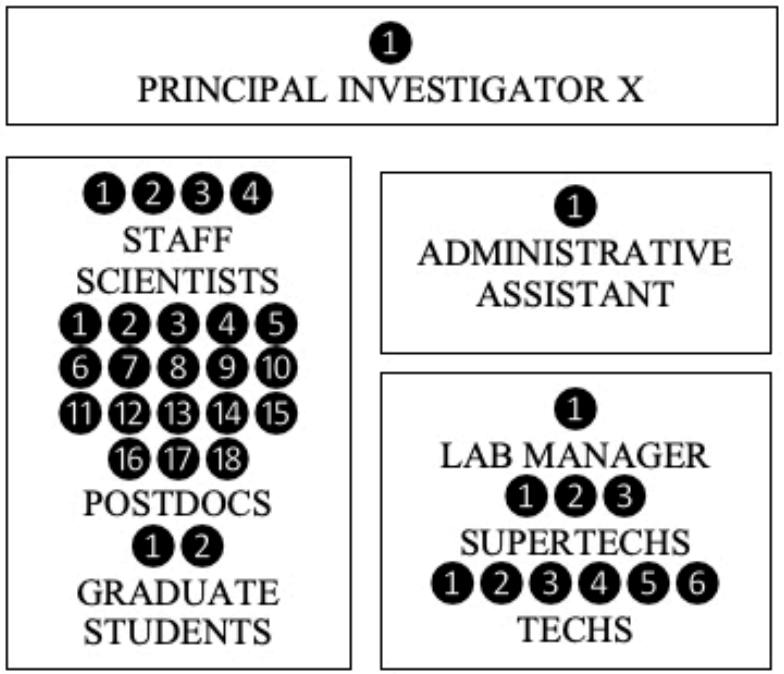

GEL-X

Figure 4: A comparison of laboratory hierarchies.

Another structural difference can be found among the changes in personnel organization since Latour and Woolgar's time. In Laboratory Life, the authors describe "an almost perfect administrative pyramid" (Latour and Woolgar [1979] 1986, 216-217) comprised of technicians, supertechs, and professional researchers for Guillemin's lab. Although the members of Principal Investigator X's lab can still be grouped into technicians, supertechs, and professional researchers, the corresponding structure is only loosely pyramidal. Now researchers share technicians, and crucial aspects of their employment, duties, and supervision are the purview of the lab manager, rather than the researchers themselves. So there is a marked split between two groups: transient but investigative members of the lab, like the postdocs and graduate students, and the more permanent and less academic employees of the lab, such as the administrators and technicians. Compare the diagrams in Figure 4.

On the left, the personnel hierarchy of Guillemin's lab, as described by Latour and Woolgar in Laboratory Life. There was one full professor, two associate research professors, five assistant research professors, five supertechs, and ten technicians for a total of twenty-three lab members. On the right, the personnel hierarchy of GEL-X, which is more of an interactive network than a pyramid. Coincidentally, GEL-X was founded in 1979, the same year that Laboratory Life was published, and at that time had only two members: Principal Investigator $\mathrm{X}$ and one technician. But three decades later, and after an extended period of growth, there was one principal investigator (still Principal Investigator X), four staff scientists, one administrative assistant, one lab manager (the original technician), eighteen postdocs, two graduate students, three supertechs, and six technicians - for a total of thirty-six lab members.

In the more recent structure, there is a sort of division of the workforce into two separate hierarchies: the academics (staff scientists, postdocs, and graduate students), chiefly responsible for the creative aspects of the lab's scientific activity, and the technicians (management, supertechs, and techs), primarily responsible for the execution and management of the lab's scientific activity. Obviously, there is some overlap: postdocs conduct some of their own experiments, in addition to their techs, and sometimes technicians are acknowledged as authors in publications because their expertise is viewed as significant enough to have contributed to the intellectual achievement represented by a manuscript. But in general, the one group dictates 
the scientific agenda (by reading the relevant literature, designing experiments, attending data club and scientific conferences, and writing and discussing grants and manuscripts), while the other group assists with the scientific agenda (by conducting the dictated experiments) as well as maintains the environment necessary for scientific practice (by ordering supplies, organizing and cleaning the laboratory, maintaining equipment, making buffers, taking care of animals, and sending and receiving samples). In GEL-X, Principal Investigator X guides the scientific agenda (by reviewing project ideas and design, overseeing grant applications and manuscript submissions, and networking with related labs), while the lab manager, although subordinate to the principal investigator, is the one who really runs the laboratory on a daily basis, dealing with the employees, equipment, protocols, supplies, and budget. Finally, there is the administrative assistant who handles the principal investigator's schedule and correspondence, and doesn't really fit into either hierarchy, but is still instrumental to lab function. Postdocs and technicians must contact the administrative assistant in order to get time with the principal investigator.

The preceding paragraphs of this section have detailed the location, materials, layout, and personnel of GEL-X. Despite the fact that GEL-X and Guillemin's lab are both at the Salk Institute, and both are molecular biology labs, it should already be apparent that the old and the new ethnographic data sets differ somewhat. This is not surprising given the passage of time as well as distinct foci for the laboratory work. The crucial question, however, is whether these differences between the data sets translate into different interpretive structures for the ethnographies, or not. In order to answer this question, we must compare not just the data but also the results of the two studies, by looking at the fit between the ethnographic data and Latour and Woolgar's interpretation of that data. That conjoined fit between data and interpretation constitutes the real outcome(s) of a study-not merely its data; rather, its results.

\section{Re-Assessing the Conceptual Framework}

Latour and Woolgar's conceptual framework for interpreting their ethnographic data includes a host of interesting ideas: ethnography, reflexivity, daily activity, the observer's story, literary inscription, origin stories, fact construction and microprocessing, statement types, cycles of credit, and the creation of order out of disorder (just to name a few). This section of the paper will assess how well Latour and Woolgar's original concepts apply to the newer observations of scientific practice. Discussion of Latour and Woolgar's concepts will proceed roughly in the order in which Latour and Woolgar originally introduced them; however, at times this order will have to be disrupted, so as to elucidate complex relationships among the ideas.

\section{The daily activity of science}

While conducting their ethnography, the authors of Laboratory Life chose to adopt what they called "an anthropological perspective." As a result, Laboratory Life begins with an excerpt from Latour's field notes - a detailed description of what he observed occurring during everyday scientific practice. His notes provide a sense of what it might be like to be a fly on the wall of Guillemin's lab in the seventies:

6 mins. 20 secs. Bill comes from the chemistry section and gives Spencer a thin vial: "Here are your two hundred micrograms, remember to put this code number on the book," and he points to the label. He leaves the room.

Long silence. The library is empty. Some write in their offices, some work by windows in the brightly lit bench space. The staccato noise of typewriting can be heard from the lobby. 
9 mins. Julius comes in eating an apple and perusing a copy of Nature.

9 mins. 10 secs. Julie comes in from the chemistry section, sits down on the table, unfolds the computer sheets she was carrying, and begins to fill in a sheet of paper. Spencer emerges from his office, looks over her shoulder and says: "hmm, looks nice." He then disappears into John's office with a few pages of draft.

9 mins. 20 secs. A secretary comes in from the lobby and places a newly typed draft on John's desk. She and John briefly exchange remarks about new deadlines.

9 mins. 30 secs. Immediately following her, Rose, the inventory assistant, arrives to tell John that a device he wants to buy will cost three hundred dollars. They talk in John's office and laugh. She leaves. (Latour and Woolgar [1979] 1986, 15-16)

Despite the passage of decades, it is still possible to observe a very similar sort of scene. Here is an excerpt from field notes gathered on an unremarkable morning in GEL-X:

9:09am: Two postdocs enter while conversing. One says: "So, you're working on macrophages too?" The other responds inaudibly. The first says something back and then asks "How many can you fit on a ten [inaudible]meter dish?" They pass out of earshot. The telephone rings for the first time today, but only once.

9:28am: Several more lab members enter the lab. Some go to their benches and desks. One enters the far cold room. Another does something in the kitchen. Water is running. Glasses clink. A grad student pops chewing gum while reading. A technician looks in a drawer while holding a cell phone to their ear. The technician is wearing a lab coat.

9:30am: The phone rings repeatedly in the lab manager's office.

9:39am: By now there are 11 postdocs in the lab. Nine sit at their desks. Two are standing in front of their benches.

9:50am: Another postdoc enters the lab, and puts some personal equipment down on the desk next to the observer. They exchange greetings. The grad student says "Hey [postdoc's name], do you think that today I could get a little tiny sample of [certain compound]?" The postdoc replies, "no problem," then unpacks a laptop and heads to the kitchen. The computer emits a sound that indicates start-up. The grad student gets up from their desk and joins two postdocs in the kitchen. Two technicians talk at their benches.

There are a few apparent differences: obviously, technology has changed and laptops have replaced typewriters. Pieces of permanent laboratory equipment often cost much more than $\$ 300$. Finally, the scientists are just as likely to be women as men, and the technicians and assistants are just as likely to be men as women. There is no longer a high probability that most roles will correlate strongly with gender.27 Regardless of these differences, much remains the same. The scientists still read Nature, eat in and around the lab, work on papers at their desks, conduct experiments at the bench, exchange data and materials with each other, and converse informally about many aspects of practice.

\footnotetext{
${ }^{27}$ It should also be apparent that, in the field notes from GEL-X, names have been replaced with gender-neutral role identifiers. This was done in order to avoid contributing to any impressions of gender or ethnicity. In contrast, Latour's field notes do contain names. These were changed in order to preserve anonymity, but they still give some impressions of gender and ethnicity that might better be either avoided or, if mentioned, then discussed explicitly. Some such explicit discussion regarding ethnicity follows here.
} 


\section{The observer's story}

The excerpt from Latour's field notes at the beginning of Laboratory Life is immediately followed by a synthesis of the entire mass of notes gathered throughout two years of observation in Guillemin's lab. The authors call this summary of everyday scientific practice "the Observer's Story." Because it provides many points of comparison with GEL-X, it is reproduced in its entirety below:

Every morning, workers walk into the laboratory carrying their lunches in brown paper bags. Technicians immediately begin preparing assays, setting up surgical tables and weighing chemicals. They harvest data from counters which have been working overnight. Secretaries sit at typewriters and begin recorrecting manuscripts which are inevitably late for their publication deadlines. The staff, some of whom have arrived earlier, enter the office area one by one and briefly exchange information of what is to be done during the day. After a while they leave for their benches. Caretakers and other workers deliver shipments of animals, fresh chemicals and piles of mail. The total work effort is said to be guided by an invisible field, or more particularly, by a puzzle, the nature of which has already been decided upon and which may be solved today. Both the buildings in which these people work and their careers are safeguarded by the Institute. Thus, cheques of taxpayers' money arrive periodically, by courtesy of the NIH, to pay bills and salaries. Future lectures and meetings are at the forefront of people's minds. Every ten minutes or so, there is a telephone call for one of the staff from a colleague, an editor, or some official. There are conversations, discussions, and arguments at the benches: "Why don't you try that?" Diagrams are scribbled on blackboards. Large numbers of computers spill out masses of print-out. Lengthy data sheets accumulate on desks next to copies of articles scribbled on by colleagues.

By the end of the day, mail has been dispatched together with manuscripts, preprints, and samples of rare and expensive substances packed in dry ice. Technicians leave. The atmosphere becomes more relaxed and nobody runs anymore. There are jokes in the lobby. One thousand dollars has been spent today. A few slides, like Chinese idiograms, have been added to the stockpile; one character has been deciphered, a miniscule, invisible increment. Minute hints have dawned. One or two statements have seen their credibility increase (or decrease) a few points, rather like the daily Dow Jones Industrial Average. Perhaps most of today's experiments were bungled, or are leading their proponents up a blind alley. Perhaps a few ideas have become knotted together more tightly.

A Philippino cleaner wipes the floor and empties the trash cans. It has been a normal working day. Now the place is empty, except for the lone figure of an observer. He silently ponders what he has seen with a mild sense of bewilderment ... (Latour and Woolgar [1979] 1986, 16-17)

Once again, many of the things described in this narrative still pertain: there is a frenzy of movement-by technicians, students, researchers, managers, assistants, writers, and janitors, as well as by money, machines, materials, networks, and organisms of all kinds-all required by the daily activity of science. Many experiments begun during the day will continue overnight: sometimes they can be left to themselves, in buffer and on a shaker, chilling or heating, in a tissue culture hood or PCR machine; but in other cases they have to be supervised through the 
night, readings taken every two hours or animals tested at various stages of progression of a chemical or mechanical treatment. In one sense, the scientific activity of the laboratory never ceases. Even if no one is in the lab, there are animal techs in the mouse house, taking care of the subjects of the experiments, 24 hours a day, 7 days a week. Many of the postdocs take articles home to read, or edit their own manuscripts when they are not in the lab. The fact that everyone has their own personal, portable computer has produced some changes in the workplace: there are no longer secretaries who type up manuscripts, since everyone does that for themselves on their laptop, and it is harder to keep work at the lab, since everyone brings it home with them on their personal computer.

The daily activity of science in the academic laboratory is still funded by what is, in some sense of the word, charity. These scientists do not produce products that are sold on the shelves of any nearby stores. Any profit derived from their work is produced quite far away in time and space. So, academic scientists require generous investment from those who believe in the value of science - and in some sense of "value" beyond short-time monetary gain. Usually, the majority of funding comes from taxpayer dollars. The National Institute of Health (NIH) still controls most of the funding available for academic labs in the biomedical sciences in the United States.28 Scientists apply for grants, which are evaluated by panels of experts in related fields, and funds are distributed to approved projects. 29 GEL-X, however, gets only a portion of its funding from federal grants. It has the good fortune of being a Howard Hughes Medical Institute (HHMI) lab, which means that GEL-X has a large percentage of its budget secured every year without having to rely on grant applications. HHMI is one of the largest philan-

\footnotetext{
${ }^{28}$ In 2007 (a year somewhat close to when this ethnography was conducted, and one for which precise comparative data has been helpfully prepared [Loscalzo 2006]), the NIH was responsible for approximately $27 \%$ of spending in support of all biomedical research in the United States - by far the largest contribution by any single agency. The pooled contribution of "industry" (including pharmaceutical, biotech, and medical device firms) contributed another 58\%, with the remaining 15\% coming from other federal, state, and local governmental agencies as well as foundations, charities, and other non-profit funds. In other words, the NIH controls more than a quarter of all the funding for biomedical research in the United States, whether for profit or not.

Narrowing the focus to academic biomedical research-considering only the financial support of biomedical research at colleges and universities in the United States-reveals that the federal government's share of the expenditures jumps to $65 \%$, with the next nearest contributor being the institutions themselves, at $18 \%$. For every $\$ 2$ spent in a biomedical research lab at an American college or university, at least one of those dollars is from the NIH.

With regards to the agency's total funds: in April of 2010 (about six months after his initial appointment in August of 2009), Francis Collins (the still-current director of the NIH) appeared before a Congressional subcommittee to request a budget of 32.1 billion dollars for the NIH in the 2011 fiscal year. In terms of taxpayer dollars, that amounts to about $\$ 100$ per capita per year. In contrast, national defense spending adds up to about $\$ 1600$ per capita per year-16 times the annual per capita rate spent in biomed.

Many of the basic figures presented in this note are derived from Loscalzo (2006).

${ }^{29}$ Project approval depends, of course, on many factors. But one aspect of the application process worth noting is something called "areas of research emphasis." Chief among the many functions of the director of the NIH is the stipulation of these categories. These are five areas in which, for whatever reason, the director thinks that biomedical research could be significantly benefitted, in whatever way, by special attention-and this means more funding opportunities in that area.

Past areas of research emphasis have included: Minority Health, Women's Health, AIDS Research, Disease Prevention, and Behavioral and Social Sciences Research (those are the five areas of research emphasis of Harold E. Varmus, the director of NIH during the Clinton administration); or Eliminating Health Disparities, Exploiting Genomic Discoveries, Reinvigorating Clinical Research, Neuroscience Research, and Biomedical Computing (those are the five areas of research emphasis of Elias A. Zerhouni, the director of NIH during the latest Bush administration). At the start of his term as director, Collins named his five areas of research emphasis: HighThroughput Technologies, Translational Medicine, Benefiting Health Care Reform, Focusing More on Global Health, and Reinvigorating and Empowering the Biomedical Research Community.

See Collins (2010) for further discussion of his chosen themes.
} 
thropic organizations in America: it is a nonprofit medical research organization that allocates hundreds of millions of dollars a year (approximately $\$ 730$ million in 2009) to those scientists named as HHMI Investigators (approximately 350 at time of writing). Principal Investigator $\mathrm{X}$ was named an HHMI Investigator in 1985, and thus the GEL-X lab receives a majority of its funds from HHMI every year-to pay for salaries, supplies, equipment, and overhead.

The observer's story also includes mention of a Philippino cleaner. This is worth discussing briefly, since it is one of the only references to ethnicity in the entirety of Latour and Woolgar's text. Interestingly, it turns out to be not at all anomalous for Latour to have observed a Philippino working as a cleaner in the late seventies. This is because a majority of the menial laborers working at the Salk Institute around that time-as janitors and technicians, in landscaping and animal care-were Philippino. That particular ethnic group had a strong presence at the institution in that era, at least in the entry-level positions that did not require degrees from American colleges and universities. Principal Investigator X's first technician was a person of Philippino ethnicity, hired shortly after the principal investigator first came to the Salk in 1979. This technician had initially interviewed at the institute on the recommendation of another member of the Philippino community who was already employed by the Salk. It did not take long for GEL-X's first lab technician to become the lab's manager, and by the time GEL-X was thirty years old (in 2009), the position paid approximately $\$ 100,000$ a year. This was the second-highest salary in the lab at that time, less only than that of Principal Investigator X. Many technicians starting at the Salk Institute are paid an hourly wage, which-if they were full time, and at that time (in 2009) — added up to average yearly earnings between $\$ 30,000$ and $\$ 40,000$. Interestingly, it is still the case that a good portion of the techs that work in GEL-X are Philippino: the lab manager is responsible for hiring the techs, and the kind of social connection that generated that initial interview in 1979 still exists, so there is often an increased probability that an opening in the lab will be filled by someone from that community rather than another. But throughout the rest of the Salk a sort of ethnic uniformity among the so-called "menial" laborers is no longer present.

There is one more crucial point yet to be made about the observer's story: it includes the first hint at what will become a predominant theme in Laboratory Life, the fluctuating currency of statements via the central scientific practice of literary inscription.

\section{Literary inscription}

After analyzing the observations made by Latour in the laboratory, the authors of Laboratory Life go on to conceptualize the product of the observed scientific activity as literary inscription. In other words, Latour and Woolgar describe what scientists chiefly do as attempting to produce and support statements. The observer's story recounts of daily practice that "one or two statements have seen their credibility increase (or decrease) a few points, rather like the daily Dow Jones Industrial Average" (Latour and Woolgar [1979] 1986, 16-17). But this report-of scientific activity as concerned mainly with literary inscription-represents a divergence from how scientists themselves commonly describe their activity. Scientists themselves tend to emphasize problems and puzzles - a point which Latour and Woolgar acknowledge in the observer's story, writing that "the total work effort is said to be guided by an invisible field, or more particularly, by a puzzle, the nature of which has already been decided upon and which may be solved today" (Latour and Woolgar [1979] 1986, 16).

With respect to the new ethnographic data, there are two interesting things to note about this disagreement. First, scientists still commonly describe scientific activity as predominantly occupied with puzzle solving. When asked why they chose to go into science, scientists in GEL- 
$\mathrm{X}$ commonly explained their decision by referring to puzzle-solving, making claims such as "I really like to solve problems" 30 and "I love the feeling of figuring something out, like a puzzle." 11 And second, here Latour and Woolgar are demonstrating their adoption of the anthropological perspective. They are not accepting self-reports from the scientists themselves as a sufficient description of what the scientists are doing. The scientists say that they are solving puzzles, guided by an invisible field, but Latour and Woolgar claim instead that scientists are engaged in literary inscription, making statements and getting others to believe that these statements represent facts.

\section{Origin stories}

The particular question of how to best describe scientific activity (as problem or puzzle solving activity as opposed to literary inscription) will be returned to in the next subsection's discussion (of fact construction). This subsection's discussion (of origin stories) details another way in which taking the anthropological perspective generates disagreement between the authors of Laboratory Life and the scientists they study.

When the scientists were asked what they worked on by non-members of the lab, Latour observed that the scientists often claimed to work "in neuroendocrinology." To the scientists, this field represented a bounded space that contained the problems they tried to solve, or the things that any statements they produced were about. Latour and Woolgar discussed the scientists' description of their field of neuroendocrinology, but with some degree of skepticism:

Our observer noticed that when asked by a total stranger, members of the laboratory replied that they worked (or were) "in neuroendocrinology." They went on to explain that neuroendocrinology was the result of a hybridization which had taken place in the 1940s between neurology, described as the science of the nervous system, and endocrinology, the science of the hormonal system. It occurred to our observer that such location "in a field" facilitated the correspondence between a particular group, network, or laboratory and a complex mixture of beliefs, habits, systematized knowledge, exemplary achievements, experimental practices, oral traditions, and craft skills. Although referred to as the "culture" in anthropology, this latter set of attributes is commonly subsumed under the term paradigm when applied to people calling themselves scientists. Neuroendocrinology seemed to have all the attributes of a mythology: it had its precursors, its mythical founders, and its revolutions. (Latour and Woolgar [1979] 1986, 54)

The fact that the authors of Laboratory Life are describing as a mythological origin story what to the scientists represents a historical account of the creation of their field indicates another point of significant disagreement between them.

So, scientists from Guillemin's lab routinely provide the hybridization account as an explanation of the genesis and object of their research, and yet Latour and Woolgar discredit the authenticity of this activity with their manner of describing it. They describe the scientists of the lab as "a strange tribe who spend the greatest part of their day coding, marking, altering, correcting, reading and writing" (Latour and Woolgar [1979] 1986, 49). Every tribe has a particular culture, where culture is understood "to refer to the set of arguments and beliefs to which there is a constant appeal in daily life and which is the object of all passions, fears, and respect" (Latour and Woolgar [1979] 1986, 55). Latour and Woolgar imply that the scientist's particular

\footnotetext{
${ }^{30}$ This comment was made during a formal, recorded interview on February 1, 2011.

${ }^{31}$ This comment was made during informal discourse on February 5, 2010.
} 
story of the hybridization of neurology and endocrinology into their field of neuroendocrinology is mostly fabricated when they write that "the mythology through which a culture represents itself is not necessarily entirely false" (Latour and Woolgar [1979] 1986, 55).

But beyond their general reasons for taking an anthropological perspective, particular reason for the authors' disbelief in this instance is not made explicit. In fact, Latour and Woolgar admit that an examination of the literature reveals a surge of papers related to the field at the time indicated by the origin story. The most specific criticism they make when describing the historical/mythological account is that:

As in many mythological versions of the scientific past, the struggle is now formulated in terms of a fight between abstract entities such as models and ideas. Consequently, present research appears based on one particular conceptual event, the explanation of which only merits scant elaboration by scientists. (Latour and Woolgar [1979] 1986, 55)

This quotation hints at what is in fact a central objection Latour and Woolgar have-namely, to the stripping of concrete entities and a rich context from a scientific account-and is a precursor of what will turn out to be the central point of contention between the scientists' own report of their activity and Latour and Woolgar's distinct characterization of that activity. In this case, the account of interest is an origin story. But a review of the text of Laboratory Life demonstrates that the authors see this behavior - a sort of stripping away of concrete context, facilitating a reorientation around abstract entities - throughout the practice of science. And Latour and Woolgar object to this practice throughout their text, which helps to explain why they characterize scientific activity via literary inscription, as well as why they describe fact elucidation as a process of construction rather than discovery.

Interestingly, gene expression is a field that - like neuroendocrinology-has an origin story of its own genesis via the hybridization of two fields. When asked about the origin of their area of research, members of GEL-X often describe an eventual synthesis between two split traditions, one in clinical medicine (specifically dealing with hormone physiology) and the other in molecular biology (referring to early attempts to investigate genetics through virology). Those being indoctrinated into the traditions and culture of the lab may accept this account as given. But what Laboratory Life helps to show is the way in which these tribal rituals can obscure the many complexities of field creation. By eliminating the details of the persons, places, and materials involved in a synthesis of scientific fields, it can seem as if it is simply a void in the space of ideas that brings a field into existence. But there are many such spaces, and not all of them are filled. Those that are filled come into existence not just because of the possibility, but also because of the actuality of the circumstances of the people, places, and materials that coalesce.

Recognizing this complexity greatly enhances the account one can provide for the origin of the area of research known as gene expression. For example, some of the founders of this particular field were scientists with experience both in medicine and in virology. The principal investigator of GEL-X was a pre-med student in undergrad, whose father was a doctor. Principal Investigator $\mathrm{X}$ went to graduate school in microbiology, and worked with bacteria and viruses during graduate study. The presence of scientists with this sort of familiarity with both fields, at a certain time, interacting at certain conferences, and investigating certain questions of peculiar interest, helps to better explain how such a synthesis between the two fields could have occurred, beyond the abstract account of simply putting two groups of ideas and methods together. It is not just the ideas that have to fit together: there also have to be people familiar with both, capable of applying them to each other; problems that might be solved with the appli- 
cation of just such a novel approach; and these problems have to have the kind of traction that secures funding and interest. By identifying each of these factors one can begin to construct a rich, complex, and more complete account of the origin of any field-not just gene expression. The point made here is that an overly mythologizing account of the origin of scientific (sub)fields-like the account provided by Latour and Woolgar in Laboratory Life-somewhat obscures the important role that material and social factors can play in explaining why certain (sub)fields come into existence and why others do not, despite a potential space for them in the realm of scientific opportunity.

\section{The (social) construction of scientific facts}

In chapters 3 and 4 of Laboratory Life, Latour and Woolgar develop their most controversial conception, that of fact construction. The following quote helps to explain this transition:

Whereas other tribes believe in gods or complicated mythologies, the members of this tribe insist that their activity is in no way to be associated with beliefs, a culture, or a mythology. Instead, they claim to be concerned only with "hard facts." (Latour and Woolgar [1979] 1986, 70)

This brings the discussion back to the aforementioned disagreement over Latour and Woolgar's characterization of scientific practice as predominantly concerned with literary inscription. Although "the production of papers is acknowledged by participants as the main objective of their activity" (Latour and Woolgar [1979] 1986, 71), the scientists surveyed by Latour still objected to the authors' characterization of scientific activity as constituted by literary inscription of types of statements-in other words, by fact construction rather than discovery.

The authors of Laboratory Life explain:

Indeed, our observer incurred the considerable anger of members of the laboratory, who resented their representation as participants in some literary activity. In the first place, this failed to distinguish them from any other writers. Secondly, they felt that the important point was that they were writing about something ... (Latour and Woolgar [1979] 1986, 53)

In other words, disagreement arose mainly because Latour and Woolgar's characterization of scientific practice as literary inscription failed to mention that the process of inscription is about something: facts (in particular, facts about the world). The authors' characterization also failed to mention that the specific facts of interest to any particular laboratory are purportedly those demarcated by identification with a particular field, such as neuroendocrinology or gene expression. Putting these two points together: the scientists observed by Latour maintained that there exists a robust, dependent interaction between facts and fields in scientific practice-an interaction that was not captured by Latour and Woolgar's characterization of science as concerned with literary inscription and origin stories. In both cases- the description of scientific activity as literary inscription and the characterization of accounts of field formation as origin storiesthe authors of Laboratory Life move away from the observed scientific emphasis on facts about the world and its divisions, and toward a concern with narrative devices such as statements and stories.

Unsurprisingly, the presentation of scientific facts as (socially) constructed remains one of the most contentious aspect of Laboratory Life. 32 The idea of construction rather than discovery

\footnotetext{
${ }^{32}$ The term 'social' is included in parenthesis prior to the term 'construction' because of Latour and Woolgar's inconstancy regarding its inclusion. The initial (1979) subtitle of Laboratory Life included 'social' but the revised
} 
persists throughout Latour and Woolgar's account of scientific practice, constitutes a point of significant contention between the authors as science studies scholars and the lab members as practicing scientists, and is still of major interest to sociologists, historians, and philosophers of science as well as other science studies scholars. Because this is one of Laboratory Life's most wellknown and contested concepts, I will not attempt to reiterate the details of Latour and Woolgar's account of fact construction and the ensuing debate about it here (but see Tilley 1981; Hacking 1988, 1999; Weinart 1992; among others). Instead, I will simply report that this observer noted, while conducting this replication study, that the scientists of GEL-X protested-and just as vociferously-as those scientists in Guillemin's lab in the seventies protested against constructivist accounts of their own practices.

\section{Statement types}

If facts are not discovered but constructed, then how are they given the appearance of facticity, the sheen of discovery? One part of Latour and Woolgar's answer to this question (what might be termed the negative account) has already been discussed: that of the stripping away of historical and social context from the practice of science. But there is another component to their answer (which might be termed the positive account), one that relies on another conception introduced somewhat earlier in Laboratory Life: that of performing operations on statements in order to transform them into certain types. The former practice (stripping away context) eradicates; the latter (manipulating statements) enhances.

Latour and Woolgar classify the statements they find according to a type system based on the degree of facticity with which these statements are imbued. Type 5 statements refer to facts so taken-for-granted that they are rarely even mentioned. Type 4 statements refer to similarly uncontroversial facts, but they are at least stated explicitly. Type 3 statements are qualified by indicating their claim to fact-hood rather than simply being stated as fact. Type 2 statements are openly acknowledged claims as opposed to established facts. Type 1 statements are mere hypotheses. Using this categorization schema, Latour and Woolgar are able to conceptualize laboratories as places whereby scientists engage in the process of literary inscription in an effort to transform their statements into facts. As they put it:

A laboratory is constantly performing operations on statements; adding modalities, citing, enhancing, diminishing, borrowing, and proposing new operations. Each of these operations can result in a statement which is either different or merely qualified. Each statement, in turn, provides the focus for similar operations in other laboratories. (Latour and Woolgar [1979] 1986, 86-87)

This, then, is how scientific facts come into existence out of scientific statements, after the social and historical context of these statements has been stripped away. Laboratories produce literary inscriptions containing scientific statements, and these statements fluctuate in type according to the degree of facticity that they acquire. As statements progress up the scale-into types 3 , then 4, and eventually 5-facts are born.

Latour and Woolgar are particularly interested in one part of this story: that "the function of literary inscription is the successful persuasion of readers, but the readers are only fully convinced when the sources of persuasion seem to have disappeared" (Latour and Woolgar [1979]

(1986) subtitle did not. According to the postscript of the later version, the term was dropped because "by demonstrating its pervasive applicability, the social study of science has rendered 'social' devoid of any meaning" (Latour and Woolgar [1979] 1986, 281). For more on the meaninglessness of the term 'social' and how to re-imbue it with significance, see Latour (2005). 
1986, 76). According to the authors, diminished reference to sources of support for a statement indicates increased acceptance of the statement as fact. Of course, it is a matter of some controversy whether such sources of support disappear because a statement is demonstrably acceptable, or the statement becomes accepted via the disappearance of such sources of support. Regardless, and once again, a process of concrete and contextual stripping seems to be occurring as a fundamental aspect of scientific practice. But such statements are also tagged and placed in ways which indicate, to those familiar with the scientific signals, to which type (1-5) any given statement belongs. So the operations being performed on scientific statements are not entirely negative: rather, certain bits of context are being stripped away, while other bits of identifying information (though this information may be obscure to most outsiders) are being added.

In an effort to describe the processes by which sources of persuasion are removed from statements and how such statements are marked as a certain type (or, how a statement comes by be made and then eventually accepted as fact), Latour and Woolgar presented a detailed case study from Guillemin's lab. The authors called their case study "the construction of a fact: the case of TRF(H)" (Latour and Woolgar [1979] 1986, 105), and it tells the story of a major accomplishment for the laboratory: the elucidation and acceptance of the structure of a particular molecule, thyrotropin releasing factor/hormone.

Of course, GEL-X has its own literary inscriptions. The laboratory has produced many manuscripts filled with statements in various stages of facticity, and the scientists of the laboratory perform their own operations, moving the statements along the scale of types, hoping to establish certain claims as fact. Probably the central accomplishment of Principal Investigator X's laboratory has been the elucidation of the nuclear receptor superfamily. Here is a brief scientific description of this entity, from a review article written after about 15 years of dedicated, focused work on this topic had been conducted:

The nuclear receptor superfamily is comprised of over 150 different proteins that have evolved to mediate a complex array of extracellular signals into transcriptional responses. Many, but not all, of these proteins directly bind to signaling molecules, which, because of their small lipophilic character, can easily enter the cell. Thus, unlike membrane-bound receptors, the nuclear receptors are intracellular and function to control the activity of target genes directly. In aggregate, these target genes comprise a genetic network whose coordinate activity defines the physiological response. (Manglesdorf and Evans 1995, 841)

Latour and Woolgar's characterization of scientific practice suggests various ways to enrich this account. The simply stated paragraph quoted above contains many statements, each of which has its own distinct history. For example, the identification of the various members of the family was a venture involving several labs, including GEL-X, and which took place over many years. And each of the statements in the above paragraph may belong to any of the five statement types.

Or they might belong to several, when there is active disagreement. For example, the final sentence quoted is actually quite a controversial one. More than twenty years after the publication of the quoted review, Principal Investigator $X$ and the rest of GEL-X are still attempting to persuade other members of the gene expression community that the network of genes targeted by the nuclear receptor superfamily is what defines the physiological response. Outside the gene expression community, very different notions of what comprises the physiological response are advocated and applied. So, members of GEL-X would probably classify the statement that "these target genes comprise a genetic network whose coordinate activity defines the physiological response" as type 4 on Latour and Woolgar's scale. Members of rival labs also working 
on nuclear receptors with an alternate classification scheme might classify it as type 2 . Others within the gene expression community, aware of a certain balance between consensus and agreement, would probably label the statement as type 3. And outside of gene expression, scientists with alternate conceptions of what defines the physiological response (perhaps an organ-based rather than a molecular notion) might consider the statement type 1 , or simply think of it as false.

Even without discussion of the potential context-relativity of the typing of certain statements, Latour and Woolgar's general analysis of scientific practice helps to enrich understanding of what is presented in the scientific product as baldly stated fact. There is a scientific process by which laboratories produce literary inscriptions - transforming materials, organisms, equipment, and technical expertise into data which is then translated into statements contained in manuscripts-but there is also a correspondingly scientific process by which these statements are operated on-sliding them up and down the scale of types 1 through 5. Both processes act in a way that strips the products of the context of their production, but the latter also serves to cloak uncertainty and dissent within science. Although the statements may by tagged in ways which are discernible to scientists, to those unfamiliar with the signaling associated with statement types these statements may seem to all have the same blanket status as hard scientific facts.

This discussion occupies a somewhat privileged epistemic position, as a product of extensive observation of and experience in GEL-X. This familiarity grants access to the increased complexity surrounding the claims stated so simply in the articles produced by the laboratory. But this is not information available to everyone. To those without access, the statements might all seem to have the ring of certainty and the sheen of facticity. This is unfortunate, but interesting: it shows the way in which the negative process of context-stripping, and the positive process of replacing this context with an obscure sets of signals discernible only to those in the know, can both contribute to the construction of scientific facts and simultaneously hide the traces of that construction, at least from those who are not meant to see them.

\section{The microprocessing of facts}

It is a matter of some interest that these scientific processes encourage a sort of layering of information, concealing from many the dissent and uncertainty behind the presentation of statements as pure fact. At the very least, such practices must encourage misinterpretation of some statements, as more or less certain or established than they might actually be. So, what might explain this procedure? Latour and Woolgar examine some possible answers to this query during their investigation of "the microprocesses whereby facts are socially constructed" (Latour and Woolgar [1979] 1986, 152). In this discussion (in chapter 4) they offer some insight into why a more complete account of an actual, concrete process of fact construction might be stripped of its context and presented via a simpler account of a more abstract process:

By transforming the second account into the first, the teller transforms a localized, heterogeneous, and material set of circumstances (in which social factors are clearly visible) into the sudden occurrence of a personal and abstract idea which bears no trace of its social construction. (Latour and Woolgar [1979] 1986, 170)

So the stripping process removes unwanted traces of social construction. There has been extensive discussion of the widespread tendency to emphasize objectivity in science, and to eliminate social factors (e.g., Hempel 1983; Douglas 2004; Daston and Gallison 2007). In Laboratory Life, the authors mention this during their discussion of the commonly-assumed divide between social and scientific (or technical or intellectual) factors influencing scientific practice. These are 
other, common ways of discussing the supposed distinction between external and internal factors in science. Latour and Woolgar do not accept the validity of this distinction, but they do acknowledge the common perception that the distinction holds, particularly among scientists themselves.

Given that the externality of social factors is a widely adopted norm for scientific activity (Merton 1942), it is not difficult to understand why scientists might engage in processes that would eliminate mention of social factors and a richer context from their accounts, despite the somewhat misleading nature of this activity. The stripping process results in a sort of purification, increasing the credibility of the scientific product, by making it more in line with the standard norms of scientific practice. Interestingly, Latour and Woolgar deny that the majority of scientists are strongly motivated by these norms. For example: "the explanatory power of norms falls well short of our objective of understanding both science and the scientists who make it" (Latour and Woolgar [1979] 1986, 190); and "appeals to norms were extremely rare among our respondents" (Latour and Woolgar [1979] 1986, 190). It is not entirely clear why this lack of appeal should count as evidence for Latour and Woolgar, since they claim not to be taking the scientists' own proclamations at face value. Regardless, even without most scientists being motivated by the norms themselves, they can still be motivated by the enhanced credibility that the adoption of predominant norms will produce.

\section{Cycles of credit}

As Latour and Woolgar demonstrate throughout their discussion of cycles of credit (in chapter 5), credibility has great import for scientific activity. They explain:

Scientists' behavior is remarkably similar to that of an investor of capital. An accumulation of credibility is prerequisite to investment. The greater this stockpile, the more able the investor to reap substantial returns and thus add further to his growing capital. (Latour and Woolgar [1979] 1986, 197)

Scientists' accumulation, preservation, and employment of credibility, which acts as capital in the scientific "market," are essential to their successful practice of science. Laboratory Life documents the extensive degree to which scientists in Guillemin's lab are concerned with credibility and credit. This is also a feature of members of GEL-X. Latour and Woolgar write that:

Scientific activity in our laboratory comprised a field of contention in which facts were produced, claims dissolved, artefacts deconstructed, proofs and arguments disproved, careers ruined, and prestige cut down. (Latour and Woolgar [1979] $1986,212)$

And this is also a strikingly apt description of current scientific activity in the lab of Principal Investigator X.

A single publication in Nature, Science, or Cell is often sufficient for a graduate student or postdoc from GEL-X to get hired as the principal investigator of their own lab. As this extensive discussion of scientific practice has demonstrated, publications such as these are produced via the generation of literary inscriptions filled with statements possessing varying degrees of facticity and interest. The extent to which other members of the scientific community (including those acting as reviewers for journals) can be convinced as to the facticity and interest of those statements will strongly influence the successful development of each scientist's career. And credibility is instrumental in any attempt to convince or persuade anyone of anything. It is therefore not at all surprising that credibility would be crucial within a field where individuals 
need to be convincing in order to succeed. Such individuals are likely to be highly motivated by the importance that development of their credibility will have on the success of their career.

Additionally, the importance of credibility persists throughout a scientist's career. Efforts to obtain credit and prestige continue even after acquiring a laboratory of one's own. One reason for this is that funding still has to be secured every year. Having lab space is no guarantee of funds with which to populate it. Even scientists with some secured funding from their home institution or via an award such as HHMI Investigator depend on their credibility when applying for additional grants, among other things.

During the first hour of being interviewed for this study, while giving a sort of evaluative history of the lab and its primary field of research, Principal Investigator X mentioned the Nobel Prize fourteen times (almost once every four minutes). Here is an example, from the transcript, of this sort of discourse:

But I think it was the shortest time from a clinical trial to a Nobel Prize. I think it was less than a year. It was like, "pow!" And it wasn't even a real clinical trial, it was just individual case reports. But everyone knew these were powerful hormones. In the end, eight different kinds of small molecules were isolated. Many Nobel Prizes in there. 33

Telling the scientific narrative in this way - as a sort of "history by award" - is understandable in light of the immense recognition and corresponding benefit that winning the Nobel and acquiring such prestige virtually guarantees for one's lab. For instance, it affects personal and professional acquisition of resources (it is comparatively rare for a Nobel winner's grant applications to NIH or NSF to get rejected), and it leads to increased credibility and hence more easily accepted publications and characterizations of statements as facts. Recognition of the fact that science is a place where credibility is the most valuable currency helps to make sense of many of the initially puzzling practices identified throughout this discussion-practices such as the emphasis on origin studies in science, the important of scientific reputation, the existence and severity of priority disputes, the telling of scientific history via scientific award, the emphasis on scientific publications over financial success, and the way grant funding follows prestige. It even explains why certain seemingly detrimental practices common to scientific activity (such as the stripping of concrete context in favor of more abstract characterization) might be not just generated but also encouraged by the norms and structure of science.

\section{The creation of order out of disorder}

In the concluding chapter of Laboratory Life (chapter 6), Latour and Woolgar summarize their characterization of scientific practice with the help of one final concept: the creation of order out of disorder. As they explain it:

In sum, then, our discussion is informed by the conviction that a body of practices widely regarded by outsiders as well organized, logical, and coherent, in fact consists of a disordered array of observations with which scientists struggle to produce order. (Latour and Woolgar [1979] 1986, 36)

But the concepts that Latour and Woolgar introduce in Laboratory Life-concepts such as daily activity, the observer's story, literary inscription, origin stories, fact construction and microprocessing, statement types, and cycles of credit - these are also the authors' own attempts to create

\footnotetext{
${ }^{33}$ This excerpt is from an unstructured interview conducted on March 13, 2009.
} 
order out of the disordered set of their observations of scientific practice. Some of Latour and Woolgar's concepts (such as daily activity, the observer's story, statement types, and cycles of credit) fit their observations in a more orderly way than others do (like literary inscription, origin stories, fact construction and microprocessing). In the latter kind of case, practitioners both then and now protest Latour and Woolgar's characterization of their experience in these terms, and since these protestations are themselves part of the data set, disorder remains. There is a difference of fit between this kind of case (where disorder lingers between observed behavior and proposed concepts of analysis), and the former kind of case (where observations and concepts have been neatly reconciled with one another). Strikingly, these differences of fit are quite well reproduced in the results of this replicative ethnography - and this parallelism will be the focus of the next and final section of this paper.

\section{Concluding Remarks}

Laboratory studies in STS have, by and large, been treated as a contrary jumble of contextuallyspecific results (which one should not expect to be replicated) and sources for characterizing all of science (which one should not expect of highly contingent, narrow accounts). Setting aside the option of abandoning intellectual integrity, and that of denying that laboratory studies are contextually specific, the argument of this paper has been that we as STS scholars face a resulting choice: either give up the way we talk about laboratory studies (as sources for characterizing all of science) or demonstrate how they might support generalization (despite their contextual specificity of origin). The latter option preserves more of current practice than the former, so the aim of the replication study documented in this paper has been to establish some range and warrant for generalizability of the results of Latour and Woolgar's classic laboratory study, Laboratory Life.

As the preceding assessment of fit between Latour and Woolgar's conceptual framework and both the new and old ethnographic data sets shows, many of the results of Latour and Woolgar's original ethnography can indeed be replicated, using Latour and Woolgar's original methodology to produce new data in a new context - one close but not identical to the original study conditions. On the one hand, much of what was most orderly about Laboratory Life's synthesis of its ethnographic data can be regenerated with the new ethnographic data. For instance: familiarity with the daily activity of science is still useful in the interpretation of observations of current laboratory work. Although elements of the data have changed between the time of Latour and Woolgar's study and now (for example, personal computers have replaced typewriters, and these pieces of equipment tend to cost around $\$ 3000$ instead of \$300-see García-Sancho 2012, November 2012, and Stevens 2013 for further discussion of this sort of change), the interpretative framework offered by Latour and Woolgar still synthesizes the data from the more recent ethnographic replication attempt. Similarly, the notion of the observer's story is still an applicable one-although in this case, the concept has been updated to include sensitivity to issues of gender and ethnicity that was somewhat lacking from Latour and Woolgar's application of the idea. The concept of statement types has also been amended: both to elucidate the authors' original focus on context stripping from scientific statements, and to emphasize the scientists' practice of adding coded signals to such statements. The context-relativity of the typing of such statements, in the case of scientific disagreement, has also been noted. Finally, the observed emphasis on cycles of credit straightforwardly reapplies to the new data, which also draws attention to the importance of prizes as a form of credit in science (to such an extent that a scientist's view of the history of science becomes a sort of history of scientific awards). 
On the other hand, disorder remains at several of the points where Latour and Woolgar's conceptual apparatus originally failed to create a compelling sense of order: in the select places where their concepts did not entirely order the observations from their ethnography, so too do these older concepts fail to bring order to the newer ethnographic data. Scientists still characterize their work as consisting in something like puzzle solving, where the puzzle is comprised by a set (the field) of actual pieces (the facts). Latour and Woolgar's contrasting interpretations-of scientific work as literary inscription and of field hybridizations as mythological origin storiesstill clash with the scientists' own descriptions of their subjects and objects. The sources and justification for this disagreement are simply not evident in either the text of Laboratory Life or in the parallel interpretation of the more recent set of ethnographic data; in this sense, the original discord is indeed replicated in the modern study. In the case of hybridization of the field under study in the recent ethnography, it helped to take seriously the scientists' reports of their histories and education, as this turned out to be an important component for understanding the emergence of this area of scientific work rather than others. Similarly, in the case of recently observed gene expression fact construction and microprocessing, it seemed like the material aspect of the scientific work was also an important component of the scientific process-one that even Latour and Woolgar recognized was not solely dependent on social forces.

The principal result of this replicative ethnography is simple but compelling: it is the knowledge that these sets of agreements (order) and disputes (disorder) - between the original ethnographic data and Latour and Woolgar's conceptual framework for interpreting that data-can be replicated in the ethnographic replication. In other words: the relative fit and lack of fit, between the conceptual machinery proposed by Latour and Woolgar and their ethnographic data, can be recreated-with the new ethnographic data and the old conceptions. The study documented in Laboratory Life is replicable; many of its principal results can largely be reproduced.

\section{Acknowledgments}

First, and most important, I would like to thank the scientists and interviewees who made this ethnographic work possible - via their generous consent, dialogue, and reflection. Thanks are also due to Bob Westman for introducing me to Latour and Woolgar's Laboratory Life; to Nancy Cartwright and Kelly Gates for guiding this ethnographic replication attempt through its earliest stages; and to John Marino and Naomi Oreskes for supervising the larger oral history project in which the replicative ethnography eventually fit. I am especially grateful to Cathy Gere for her enthusiastic support of the project, throughout its long duration. Derek Green and Adam Streed provided helpful feedback on the near-final manuscript. Finally, I would like to thank the editors and reviewers who helped to make this work better-at this and several other journals.

\section{Literature cited}

Ayar, M. C., W. K. Bauchspies, and B. Yalvac. 2015. "Examining Interpretive Studies of Science: A Meta-Ethnography." Educational Sciences: Theory \& Practice 15: 253-265.

Baker, M. 2016. “Is There a Reproducibility Crisis?” Nature 533: 452-454.

Barnes, B. 1981. "On the 'Hows' and 'Whys' of Cultural Change (Response to Woolgar)." Social Studies of Science 11: 481-498.

Bloor, D. 1976. Knowledge and Social Imagery. London: Routledge \& Kegan Paul. 
Bogen, J. 2001."Two as Good as a Hundred: Poorly Replicated Evidence in Some NineteenthCentury Neuroscientific Research.” Studies in History and Philosophy of Biology and Biomedical Sciences 32 (3): 491-533.

Bowker, G., and S. L. Star. 1999. Sorting Things Out: Classification and Its Consequences. Cambridge, MA: MIT Press.

Burawoy, M. 2003. "Revisits: An Outline of a Theory of Reflexive Ethnography." American Sociological Review 68 (5): 645-679.

Calder, B. J., L. W. Phillips, and A. M. Tybout. 1982. “The Concept of External Validity.” Journal of Consumer Research 9: 240-244.

Campbell, D. T., and J. C. Stanley. 1966. Experimental and Quasi-Experimental Designs for Research. Chicago: Rand McNally.

Clapeyron, B. P. E. 1834. "Mémoire sur la Puissance Motrice de la Chaleur." Journal de l'Ecole Royale Polytechnique XIV: 153-190.

Clarke, A. E. 2005. Situational Analysis: Grounded Theory After the Postmodern Turn. Thousand Oaks: Sage.

Collins, H. 1975. "The Seven Sexes: A Study in the Sociology of a Phenomenon, or The Replication of Experiments in Physics." Sociology 9 (2): 205-224.

Collins, H. 1985. Changing Order: Replication and Induction in Scientific Practice. London: Sage.

Collins, F. 2010. “Opportunities for Research and NIH.” Science 327: 36-37.

Conefrey, T. 1997. “Gender, Culture, and Authority in a University Life Sciences Laboratory.” Discourse E Society 8: 313-340.

Daston, L. J., and P. Galison. 2007. Objectivity. Brooklyn: Zone Books.

Doing, P. 2009. Velvet Revolution at the Synchrotron: Biology, Physics, and Change in Science. Cambridge, MA: MIT Press.

Doran, C. 1989. "Jumping Frames: Reflexivity and Recursion in the Sociology of Science." Social Studies of Science 19: 515-531.

Douglas, H. 2004. “The Irreducible Complexity of Objectivity.” Synthese 138: 453-473.

Feest, U. 2016. “The Experimenter's Regress Reconsidered: Replication, Tacit Knowledge, and the Dynamics of Knowledge Generation.” Studies in History and Philosophy of Science 58: 34-45.

Finlay, L. 2002. "Negotiating the Swamp: The Opportunity and Challenge of Reflexivity in Research Practice." Qualitative Research 2: 209-230.

Franklin, A., and C. Howson. 1984. "Why Do Scientists Prefer to Vary Their Experiments?" Studies in History and Philosophy of Science 15 (1): 51-62.

Fujimura, J. 1996. Crafting Science: Standardized Packages, Boundary Objects, and "Translation". Cambridge, MA: Harvard Univ. Press.

García-Sancho, M. 2012. Biology, Computing, and the History of Molecular Sequencing: From Proteins to DNA 1945-2000. London: Palgrave Macmillan.

Garfinkel, H. 1967. Studies in Ethnomethodology. Englewood Cliffs: Prentice-Hall.

Garforth, L. 2012. "In/Visibilities of Research: Seeing and Knowing in STS.” Science, Tecbnology, \& Human Values 37: 264-285.

Geertz, C. 1973. The Interpretation of Cultures: Selected Essays. New York: Basic Books.

Glaser, B. G., and A. L. Strauss. 1967. The Discovery of Grounded Theory: Strategies for Qualitative Research. New Brunswick: Aldine.

๑ OPEN ACCESS - PTPBIO.ORG 
Golinski, J. 1990. "The Theory of Practice and the Practice of Theory: Sociological Approaches in the History of Science.” Isis 81: 492-505.

Gooday, G. 2008. "Placing or Replacing the Laboratory in the History of Science?" Isis 99: 783-795.

Grenier, M. 1983. "Cognition and Social Construction in Laboratory Science." 4S Review 1: 2-16.

Guala, F. 2003. "Experimental Localism and External Validity." Philosophy of Science 70: 1195-1205.

Guba, E. G. 1981. “Criteria for Assessing the Trustworthiness of Naturalistic Inquiries.” Educational Communication and Technology 29 (2): 75-91.

Hacking, I. 1988. "The Participant Irrealist At Large in the Laboratory." The British Journal for the Philosophy of Science 39: 277-294.

Hacking, I. 1999. The Social Construction of What? Boston: Harvard University Press.

Hallam, S. 2013. Life Out of Sequence: A Data-Driven History of Bioinformatics. Chicago: University of Chicago Press.

Hammersley, M. 1989. The Dilemma of Qualitative Method: Herbert Blumer and the Chicago Tradition. London: Routledge.

Haraway, D. 1987. "A Manifesto for Cyborgs: Science, Technology, and Socialist Feminism in the 1980s." Australian Feminist Studies 2: 1-42.

Hempel, C. G. 1983. "Valuation and Objectivity in Science." In Physics, Philosophy and Psychoanalysis, edited by R. S. Cohen and L. Laudan, 73-100. Dordrecht: Reidel.

Hempel, C. G., and P. Oppenheim. 1948. "Studies in the Logic of Explanation." Philosophy of Science 15 (2): 135-175.

Horn, K. 2001. "The Consequences of Citing Hedged Statements in Scientific Research Articles." BioScience 51: 1086-1093.

Ihde, D. 2015. “Positioning Postphenomeonology.” In Postphenomonological Investigations: Essays on Human-Technology Relations, edited by R. Rosenberger and P. P. Verbeek, vii-xvi. Lanham: Lexington Books.

Knorr Cetina, K. 1981. The Manufacture of Knowledge: An Essay on the Constructivist and Contextual Nature of Science. Oxford: Pergamon Press.

Lakatos, I. 1970. "Falsification and the Methodology of Scientific Research Programmes." In Criticism and the Growth of Knowledge, edited by I. Lakatos and A. Musgrave, 91-196. Cambridge: Cambridge University Press.

Latour, B. 1988. The Pasteurisation of France. Cambridge, MA: Harvard University Press.

Latour, B. 2005. Reassembling the Social: An Introduction to Actor-Network-Theory. Oxford: Oxford University Press.

Latour, B., and S. Woolgar. 1979. Laboratory Life: The Social Construction of Scientific Facts. Beverly Hills: Sage Publications.

Latour, B., and S. Woolgar. 1986. Laboratory Life: The Construction of Scientific Facts, revised edition. Princeton: Princeton University Press. Originally published as Laboratory Life: The Social Construction of Scientific Facts in 1979.

Law, J. 2008. “On Sociology and STS.” The Sociological Review 56: 623-649.

Lincoln, Y. S., and E. G. Guba. 1982. "Epistemological and Methodological Bases of Naturalistic Inquiry.” Educational Communication and Technology 30 (4): 233-252.

Lincoln, Y. S., and E. G. Guba. 1985. Naturalistic Inquiry. Newbury Park: Sage Publications.

Livnat, Z. 2009. “The Concept of Scientific Fact: Perelman and Beyond.” Argumentation 23: 375-386.

๑ OPEN ACCESS - PTPBIO.ORG 
Loscalzo, J. 2006. "The NIH budget and the Future of Biomedical Research." Nerw England Journal of Medicine 354: 1665-1667.

Lynch, M. 1985. Art and Artifact: A Study of Shop Work and Shop Talk in a Research Laboratory. London: Routledge \& Kegan Paul.

Lynch, M. 2000. "Against Reflexivity as an Academic Virtue and Source of Privileged Knowledge." Theory, Culture E Society 17: 26-54.

Mack, R. W. 1951. “The Need for Replication Research in Sociology.” American Sociological Review 16: 93-94.

Mangelsdorf, D., and R. M. Evans. 1995. “The RXR Heterodimers and Orphan Receptors.” Cell 83: 841-850.

Merton, R. K. 1942. "Science and Technology in a Democratic Order." Journal of Legal and Political Sociology 1: 115-26.

Morgan, M. S. 2014. "Resituating Knowledge: Generic Strategies and Case Studies.” Philosophy of Science 81: 1012-1024.

Mulkay, M. 1984. "The Scientist Talks Back: A One-Act Play with a Moral, about Replication in Science and Reflexivity in Sociology." Social Studies of Science 14: 265-283.

Mulkay, M., and G. N. Gilbert. 1986. "Replication and Mere Replication." Philosophy of the Social Sciences 16: 21-37.

Murphy, R. 1994. “The Sociological Construction of Science without Nature.” Sociology 28: 957-974.

November, J. 2012. Biomedical Computing: Digitizing Life in the United States. Baltimore: John Hopkins University Press.

Oldroyd, D. 1987. “Science Action-Packed.” Social Epistemology 1: 341-346.

Plesser, H. E. 2018. "Reproducibility vs. Replicability: A Brief History of a Confused Terminology." Frontiers in Neuroinformatics 11: 75/1-4.

Popper, K. R. 1956. The Logic of Scientific Discovery. New York: Basic Books. Originally published in German as Logik der Forschung in 1934.

Pinch, T. 1993. “Turn, Turn, and Turn Again: The Woolgar Formula.” Science, Technology, \& Human Values 18: 511-522.

Radder, H. 1992. "Experimental Reproducibility and the Experimenter's Regress.” PSA: Proceedings of the Biennial Meeting of the Philosophy of Science Association 1992 (1): 63-73.

Rickert, H. 1962. Science and History: A Critique of Positivist Epistemology, translated by G. Reisman. Princeton, NJ: Van Nostrand. Originally published in German as Kulturwissenschaft und Naturwissenschaft in 1899 .

Ryle, G. 1968a. "Thinking and Reflecting." In The Human Agent, edited by G. N. A. Vessey, 210-226. London: Palgrave Macmillan.

Ryle, G. 1968b. The Thinking of Thoughts. University Lectures, No. 18. Saskatoon: University of Saskatchewan.

Salmon, W. C. 1998. Causality and Explanation. Oxford: Oxford University Press.

Shapin, S., and S. Schaffer. 1985. Leviathan and the Air-Pump: Hobbes, Boyle, and the Experimental Life. Princeton: Princeton University Press.

Schickore, J. 2011. "What Does History Matter to Philosophy of Science? The Concept of Replication and the Methodology of Experiments." Journal of the Philosophy of History 5: 513-532.

Shrum, W. 1984. “Scientific Specialties and Technical Systems.” Social Studies of Science 14: 63-90.

○ OPEN ACCESS - PTPBIO.ORG 
Sismondo, S. 1993. "Some Social Constructions.” Social Studies of Science 23: 515-553.

Stephens, N., and J. Lewis. 2017. "Doing Laboratory Ethnography: Reflections on Method." Qualitative Research 17 (2): 202-216.

Sterne, J. 2007. "Out with the Trash: On the Future of New Media." In Residual Media, edited by C. R. Acland, 17-31. Minneapolis: University of Minnesota Press.

Tibbetts, P., and P. Johnson. 1985. "The Discourse and Praxis Models in Recent Reconstructions of Scientific Knowledge Generation.” Social Studies of Science 15: 739-749.

Tilley, N. 1981. “The Logic of Laboratory Life." Sociology 15: 117-126.

Traweek, S. 1988. Beamtimes and Lifetimes: The World of High Energy Physicists. Cambridge, MA: Harvard University Press.

Weinert, F. 1992. "Vicissitudes of Laboratory Life." The British Journal for the Philosophy of Science 43: 423-429.

Windelband, W. 1980. “Rectorial Address, Strasbourg, 1894.” Translated by G. Oakes. History and Theory 19: 169-185. Originally published in German as "Geschichte und Naturwissenschaft" in 1894.

Woolgar, S. 1981a. "Interests and Explanation in the Social Study of Science." Social Studies of Science 11: 365-394.

Woolgar, S. 1981b. "Critique and Criticism: Two Readings of Ethnomethodology." Social Studies of Science 11: 504-514.

Woolgar, S. 1982. "Laboratory Studies: A Comment on the State of the Art." Social Studies of Science 12: 481-498.

(C) 2020 Author(s)

This is an open-access article distributed under the terms of the Creative Commons Attribution 4.0 International license, which permits anyone to download, copy, distribute, display, or adapt the text without asking for permission, provided that the creator(s) are given full credit.

ISSN 2475-3025 